\title{
Basic Microbiology
}

\section{Instructions on Laboratory Exercises}

Authors:

Maša Primec, M.S.

Tomaž Langerholc, Ph.D.

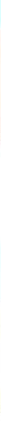




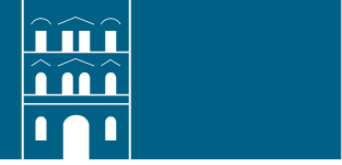

University of Maribor Press 


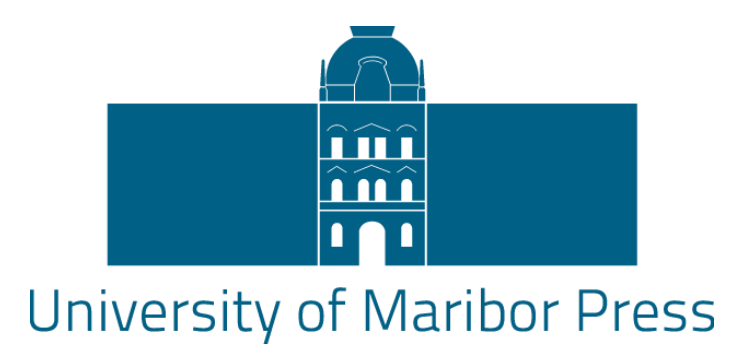

Basic Microbiology

Instructions on Laboratory Exercises

Author:

Maša Primec, M.S.

Tomaž Langerholc, Ph.D. 
Title: Basic Microbiology

Subtitle: Instructions on Laboratory Exercises

Authors: $\quad$ Assist. Maša Primec, M.S., (University of Maribor, Faculty of Agriculture and Life Sciences) Assoc. prof. Tomaž Langerholc, Ph.D., (University of Maribor, Faculty of Agriculture and Life Sciences)

Review: Assoc. prof. Janja Trček, Ph.D., (University of Maribor, Faculty of Natural Sciences and Mathematics)

Senior Research Fellow, Andrej Steyer, Ph.D., (University of Ljubljana, Faculty of Medicine, Institute of Microbiology and Immunology)

Proofreading: Katja Težak, Lang. Instr., (University of Maribor, Faculty of Agriculture and Life Sciences)

Tehnical editor: $\quad$ Assist. Maša Primec, M.S., (University of Maribor, Faculty of Agriculture and Life Sciences) Sen. Lect. Peter Berk, M.S., (University of Maribor, Faculty of Agriculture and Life Sciences)

Cover designer: Jan Perša (University of Maribor Press)

Co-published by / Izdajateljica:

University of Maribor, Faculty of Agriculture and Life Sciences

Pivola 10, 2311 Hoče, Slovenia

tel. +386232090 00, fax +38626161158

http://fkbv.um.si/.si, fkbv@um.s

First published in 2017 by / Založnik:

University of Maribor Press

Slomškov trg 15, 2000 Maribor, Slovenia

tel. +386225042 42, fax +38622523245

http://press.um.si, zalozba@um.si

Edition: 1 .

Type of publication: e-publication

Available at: http://press.um.si/index.php/ump/catalog/book/265

Published in: August 2017

\section{(c) University of Maribor Press}

All rights reserved. No part of this book may be reprinted or reproduced or utilized in any form or by any electronic, mechanical, or other means, now known or hereafter invented, including photocopying and recording, or in any information storage or retrieval system, without permission in writing from the publisher.

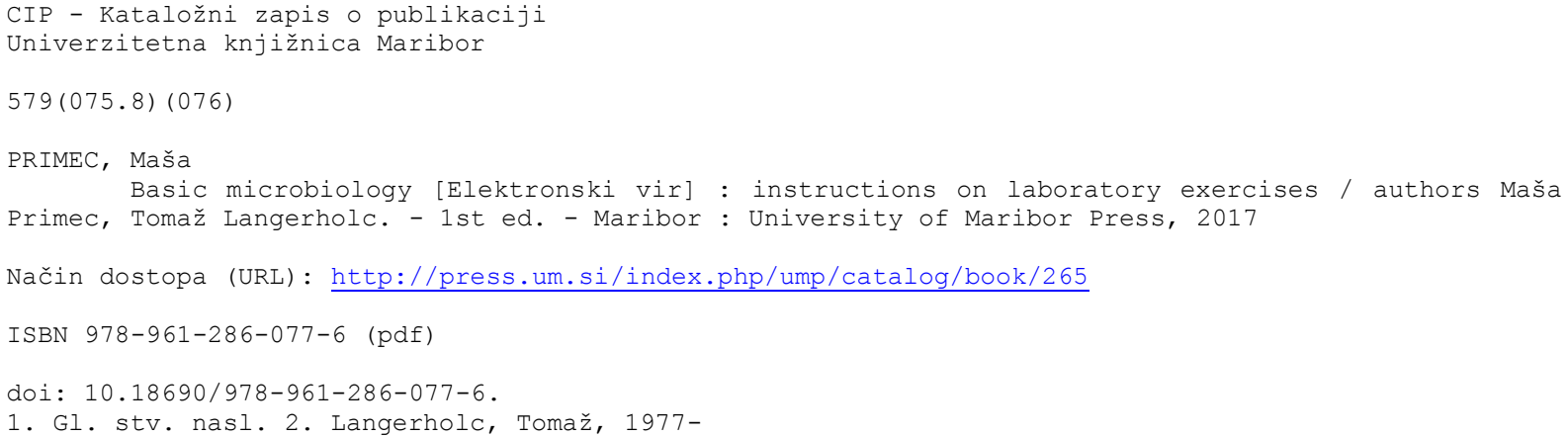

ISBN: $\quad 978-961-286-077-6$

DOI: https://doi.org/10.18690/978-961-286-077-6

Price: Free copy

For publisher: Prof. dr. Igor Tičar, Rector (University of Maribor) 


\section{Preface}

\section{MAŠA PRIMEC \& TOMAŽ LANGERHOLC}

Bridging the gap between the theoretical and the practical application of what students are learning is the first step towards understanding the central roles of microorganisms in nature and in our daily lives. Our goal for these instructions on laboratory exercises is to provide a bridge that helps our foreign students, who choose the Microbiology course (Erasmus exchange program), to integrate lectures with laboratory experience.

\section{Keywords: • Basic Microbiology • Instructions $\bullet$ Laboratory exercises}

- Microbiology course $\bullet$ Students $\bullet$

Take interest, I implore you, in those sacred dwellings which one designates by the expressive term: laboratories. Demand that they be multiplied, that they be adorned. These are the temples of the future-temples of well-being and of happiness. There it is that humanity grows greater, stronger, better.

Louis Pasteur (French chemist, founder of microbiology, 1822-1895)

CoRreSPONDENCE AdDRESS: Maša Primec, M.S., Assistant, University of Maribor, Faculty of Agriculture and Life Sciences, Pivola 10, 2311 Hoče, Slovenia, e-mail: masa.primec@um.si. Tomaž Langerholc, Ph.D., Associate Professor, University of Maribor, Faculty of Agriculture and Life Sciences, Pivola 10, 2311 Hoče, Slovenia, e-mail: tomaz.langerholc@um.si. 


\section{INDEX OF CONTENT}

INDEX OF CONTENT

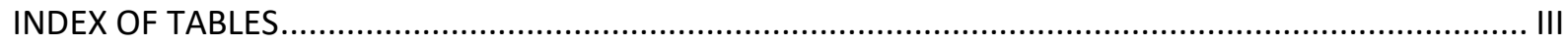

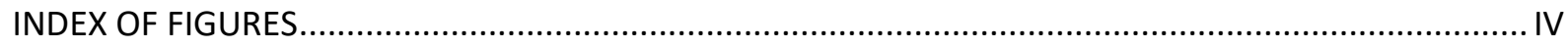

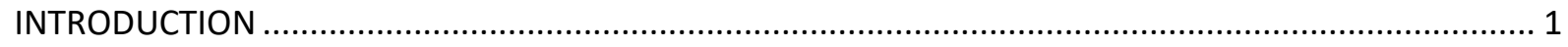

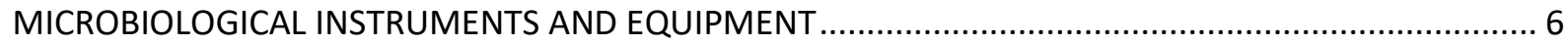

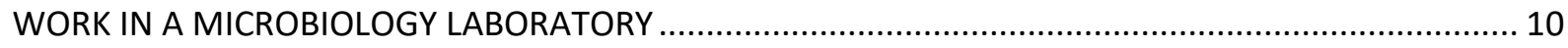

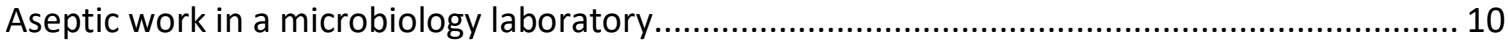

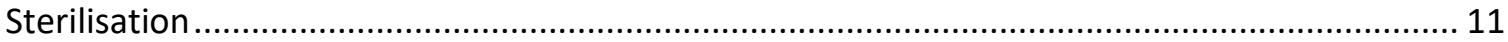

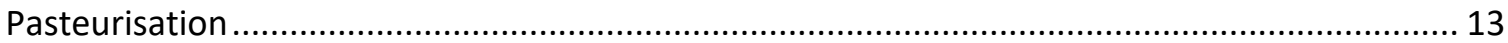

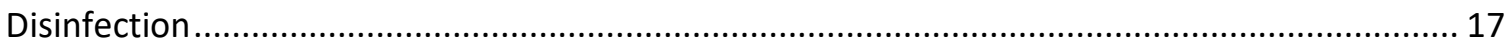

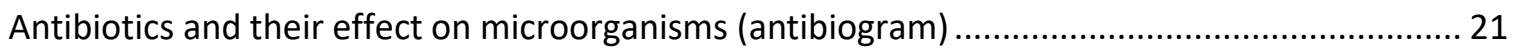

ISOLATION OF A PURE CULTURE - IDENTIFICATION OF BACTERIA .................................................. 26

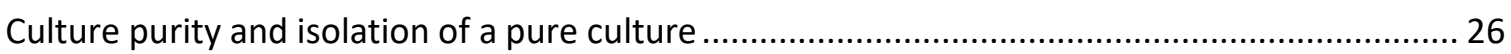

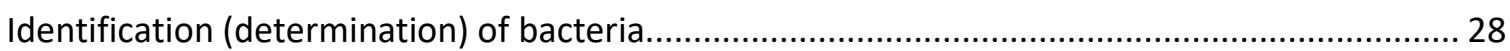

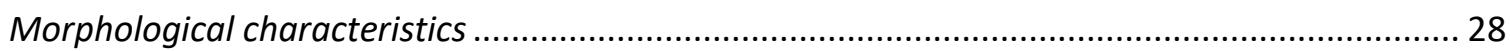

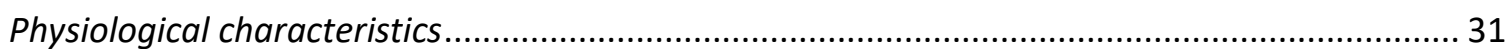

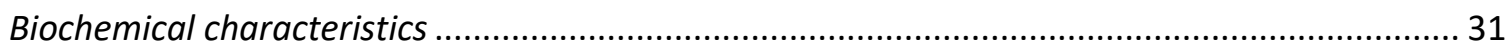

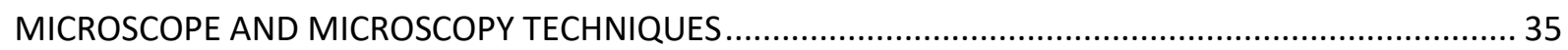

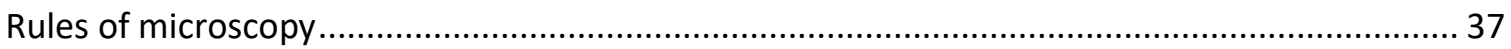

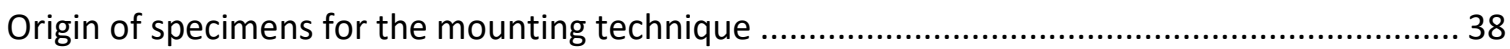

Preparation of specimens on microscopic slides (mounting) ..................................................... 38

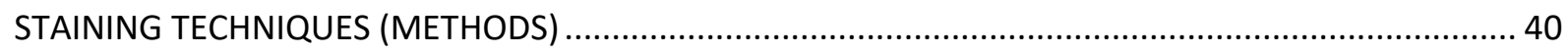

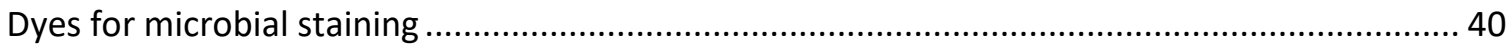

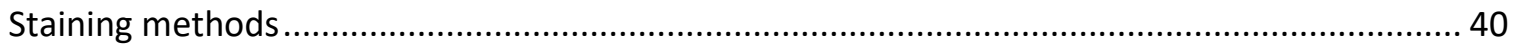

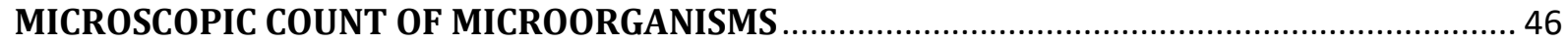

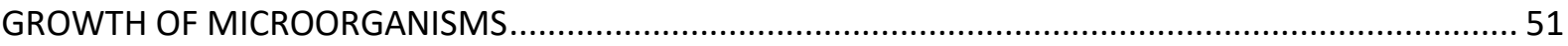

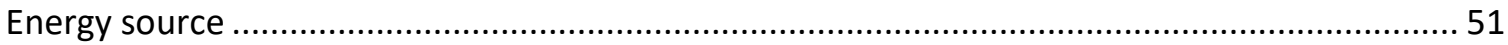

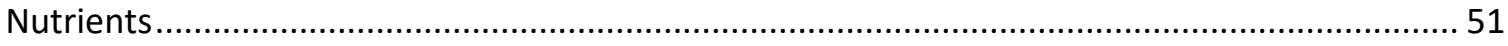

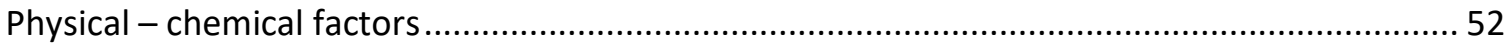

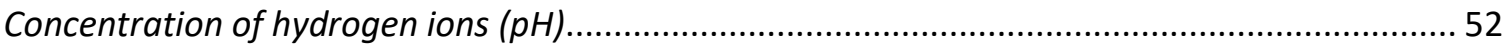

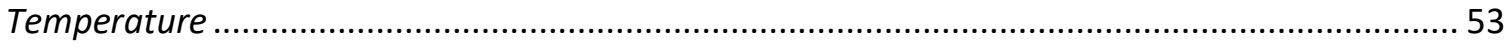

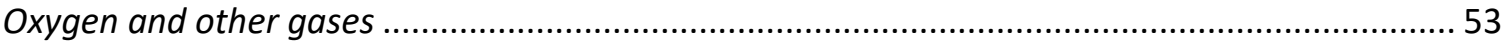

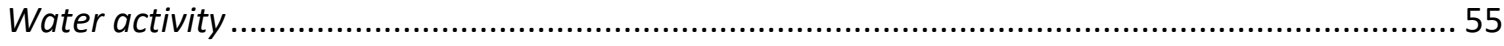

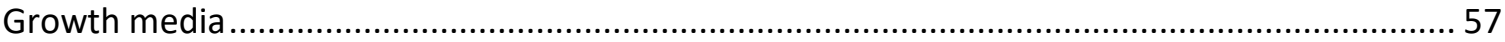


PREPARATION OF FOOD AND FEED SAMPLES FOR MICROBIOLOGICAL ANALYSIS - SAMPLING 62

Sampling instructions 62

FUNGI 67

REFERENCES 69

Cited references 69

Cited electronic references 72 


\section{INDEX OF TABLES}

Table 1: Types of pasteurisation in dairy industry

Table 2: Table of sensitivity tests of antibiotics BD BBL Sensi-Disc.

Table 3: Comparison between different types of microscopy.

Table 4: Most commonly used dyes for bacterial staining......

Table 5: Selected staining techniques and their applications......

Table 6: Most frequent elements used for the growth of microorganisms 52

Table 7: Division of microorganisms according to the growth temperature 53 


\section{INDEX OF FIGURES}

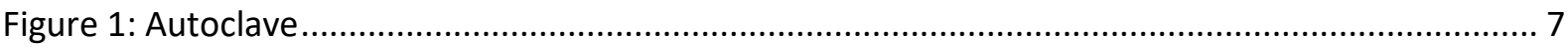

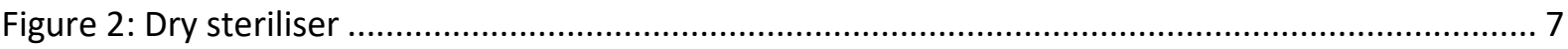

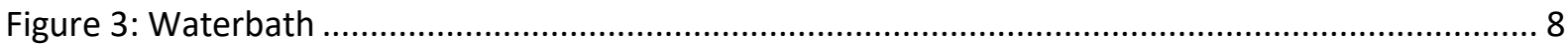

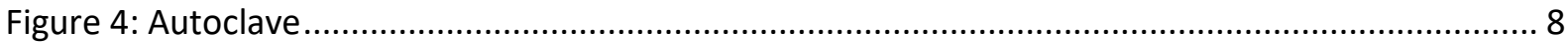

Figure 5: Centrifuge

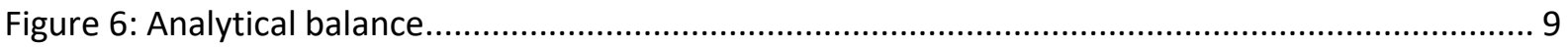

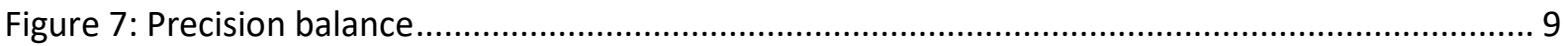

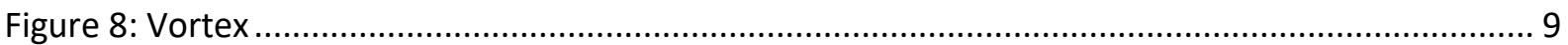

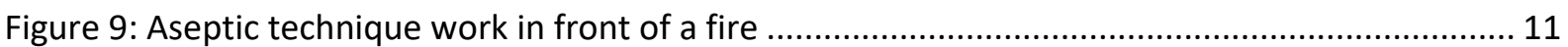

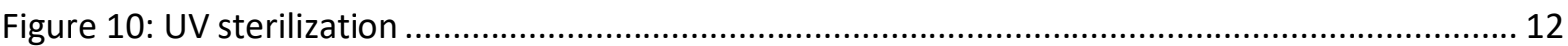

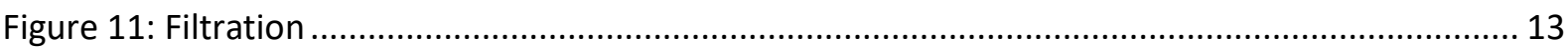

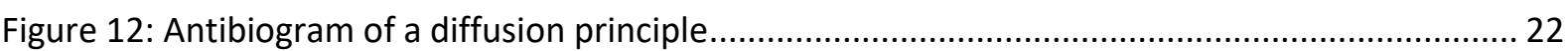

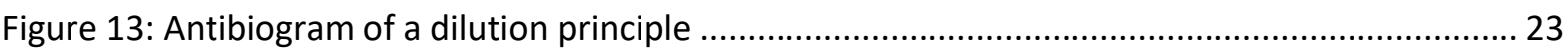

Figure 14: (A) Inoculation of bacteria into broth growth medium; (B) Transfer of bacteria onto a solid

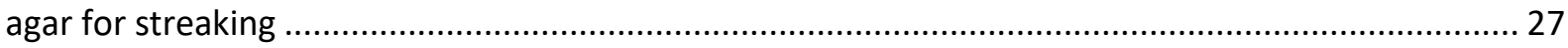

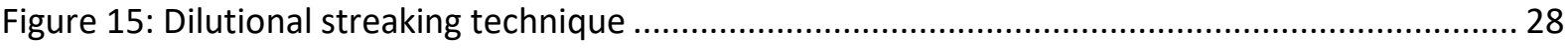

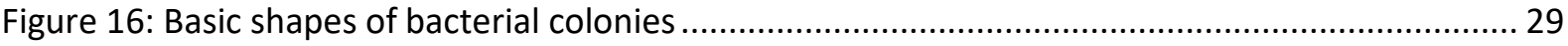

Figure 17: Basic micromorphological characteristics of bacteria......................................................... 30

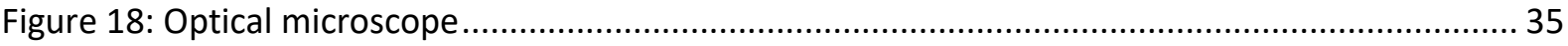

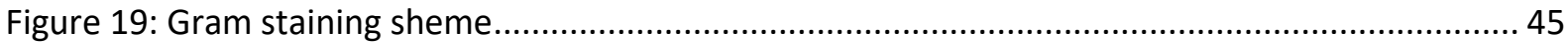

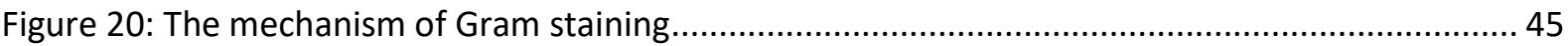

Figure 21: Haemocytometer (left) with the enlarged middle square (right) ...................................... 48

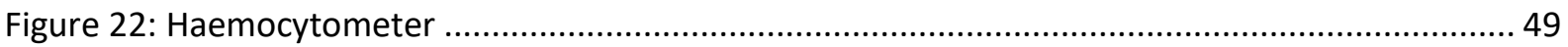

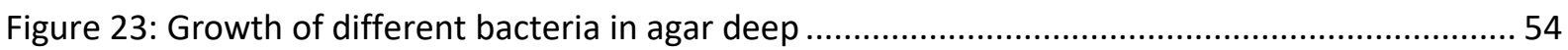

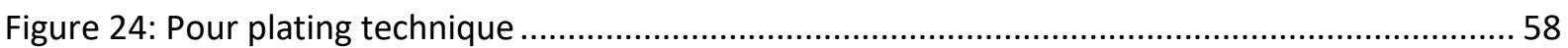

Figure 25: Sample dilution preparation and pouring technique..................................................... 65

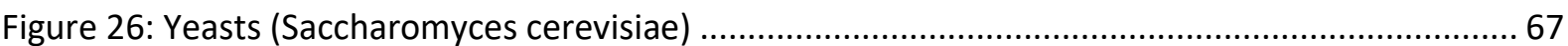




\section{INTRODUCTION}

\section{Microbiology laboratory}

The practical part of the microbiology exercises is held in a laboratory, which has its specific nature, because of work with microorganisms.

Working in a microbiology laboratory differs from working in other laboratories. It includes handling with live microorganisms, which may be potentially dangerous. Although microorganisms used in the following exercises are of nondangerous nature, they can stil be reffered to as potential pathogens. It is therefore important to always consider any and all possibilities of a potential infection outburst. 


\section{RULES, SAFETY PRECAUTIONS and PROCEEDINGS IN A MICROBIOLOGY LABORATORY}

\section{RULES}

During the laboratory exercises, it is mandatory to wear a laboratory gown. All other belongings (bags, jackets, mobile phone, etc.) are not allowed on the working desks.

It is not allowed to eat, drink, chew and smoke during the laboratory exercises!

Scratches and other incisions need to be covered with a plaster.

It is mandatory to wash your hands BEFORE and AFTER the laboratory exercises. After washing, a quick disinfection of your hands with a $70 \%$ ethanol solution needs to be done. A thorough cleaning of the laboratory material and disinfection of the working surfaces BEFORE and AFTER the laboratory exercises is essential to keep the laboratory clean.

When working with microorganisms, keep in mind that all of them can be referred to as potential pathogens!

Work carefully and aseptically close to the fire (gas burner)!

Put the contaminated material into a proper waste deposit. Microorganism cultures are not to be carried outside the laboratory!

Clearly and unambiguously label all the used material (type of microorganism, student name or group name, date, type of sample, dilution).

After finishing the exercises, make sure the gas burner is turned off. Put all the reagents and laboratory equipment (tubes, Petri dishes, pipettes etc.) back in their original place. Material, which was in direct contact with a microbial culture should be sterilized and therefore kept separate from other materials.

Keep the report of the laboratory exercises up to date!

Foreign visitors are not allowed to enter the microbiology laboratory. 


\section{SAFETY PRECAUTIONS}

Put sharp objects (needles, glasses, etc.) into proper deposit containers.

Put glass tubes into proper tube holders to prevent them from turning over.

It is not allowed to pipette with a mouth!

Put the used pipette tips into the proper deposit.

Be careful not to spill the microbial culture on the working surfaces, on the floor or on your laboratory gown! It is not allowed to touch the colonies or suspensions of live microorganisms with bare hands.

After finishing the exercises, clean all working surfaces with $70 \%$ ethanol!

\section{FOLLOW THE INSTRUCTIONS OF EXERCISE PROTOCOLS VERY CAREFULLY!}

The students need to be aware of the safety equipment usage (aseptic soap, disinfection agent, fire extinguisher etc.).

\section{PROCEEDING OF STEPS IN CASE OF AN ACCIDENT}

If an accident occurs, immediately call the lab supervisor!

If the microorganism comes in touch with the skin or working surfaces, immediately call the lab supervisor! Proceed with covering the contaminated surface with a paper towel and spill $70 \%$ ethanol over the surface of it. Leave the disinfectant to work for at least 20 minutes. Contaminated place on the body or laboratory gown need to be disinfected as well.

Pieces of broken glass need to be thoroughly cleaned and put into the proper deposit! 
DESINFECT YOUR HANDS WITH 70\% ETHANOL, IF YOU TOUCH THE MICROBIAL CULTURE! AFTERWARDS, WASH YOUR HANDS WITH WATER.

IF A MICROBIAL CULTURE SPURTS INTO YOUR EYES, WASH THEM WITH A LARGE AMOUNT OF WATER!

IF YOU PRICK YOURSELF WITH A NEEDLE OR CUT YOURSELF, LET THE WOUND BLEED FOR FEW SECONDS AND THEN CLEAN THE WOUND WITH WATER AND SOAP. DESINFECT THE WOUND WITH 70\% ETHANOL AND WRAP IT WITH A STERILE BAND.

A quick overview of the previous laboratory exercise is to be expected. A filled in report of the finished laboratory exercise should be handed in to the lab supervisor, otherwise you will not be allowed to take part in the next lab session!

PREGNANT WOMEN are not allowed to enter the microbiology laboratory, because of the potential possibility of infection with pathogenic microorganisms.

With my signature, I declare that I have read and understood the rules of the microbiology laboratory. I am aware of the potential danger involved in the work and I take full responsibility for my decision to participate in it. The staff and the faculty take no responsibility for the accidents that occur as a consequence of a failure to comply with the laboratory rules or because of unexpected accidents.

Name and Surname (block capitals):

Signature: 
REPORT ON A LABORATORY EXCERCISE

Date:

EXCERCISE number:......

GROUP number:.......

Name and Surname:

Field of study:

TITLE OF THE EXERCISE:

1. Aim of the exercise: (describe in a few sentences)

2. Description of the exercise: (describe the procedure steps in a few sentences)

3. Results: (describe and evaluate the obtained results, no matter if they are correct or not)

4. Discussion and conclusion: (discuss the point of the exercise, make comments, suggestions) 


\section{MICROBIOLOGICAL INSTRUMENTS AND EQUIPMENT}

An exercise can be performed only if the minimum of microbiological instruments and equipment are at hand in the microbiology laboratory. Laboratory equipment can be divided into equipment of working place (where the exercise occurs) and equipment of general use.

\section{Equipment of working place}

- microscope

- object / deck glasses

- inoculation loop

- gas burner

- Drigalski spatula and glass

- paper towel

- holder for glass tubes

- holder for microscopic slides

Depending on the type of exercise:

- sterile tubes, pipettes, Petri dishes, different containers, trays, tweezers, scissors, scalpels, magnifying glasses, etc.

Equipment of general use

- autoclave (steam sterilisation)

- Koch's pot

- sterilisator (dry $\left.\left(180-250^{\circ} \mathrm{C}\right)\right)$

- waterbath

- laboratory centrifuge (max. 5000 RPM)

- balance (analytical and precise)

- fridge $\left(4^{\circ} \mathrm{C}\right) /$ deep freezer $\left(-20^{\circ} \mathrm{C}\right)$

- stomacher

- vortex

- thermometer

- laminar flow 


\section{Laboratory dishes}

- tubes (glass or plastic)

- pipettes (glass, automatic)

- measuring cylinder (10 till $1000 \mathrm{~mL}$ )

- bottles and glasses (Erlenmayer glass, measure flasks, etc.)

- Petri dishes

- mortar

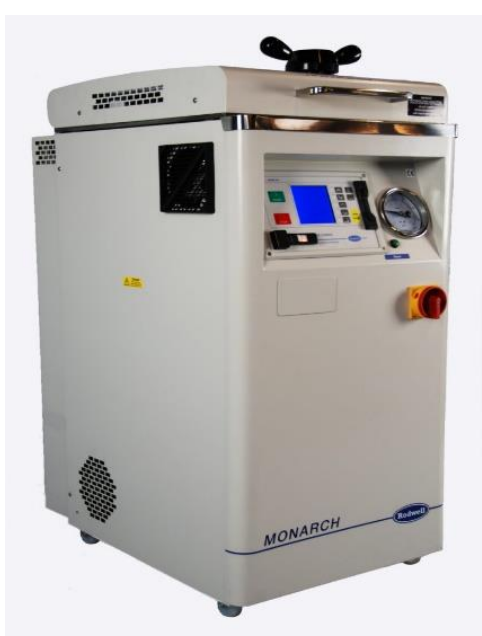

Figure 1: Autoclave.

(Source: http://www.rodwell-autoclave.com/autoclave/monarch-autoclave/).

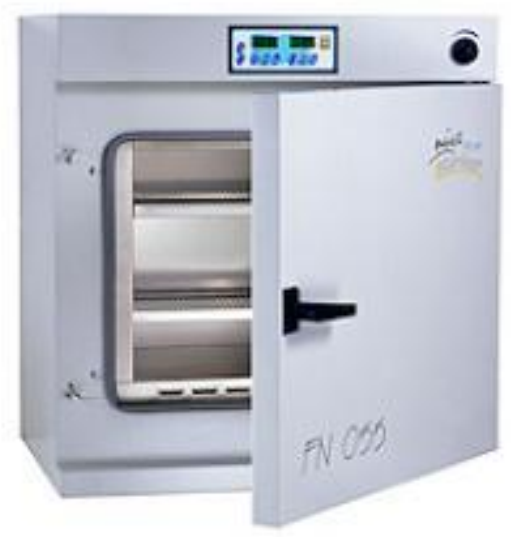

Figure 2: Dry steriliser.

(Source: $h t t p: / / w w w . n u v e . c o m . t r / e n / p r o d u c t s / f n-032-055-120-d r y$-heat-sterilizers-ovens) 


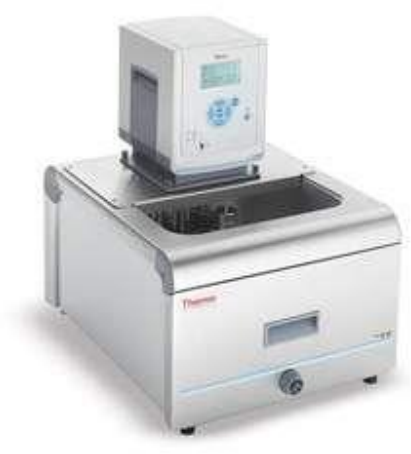

Figure 3: Waterbath.

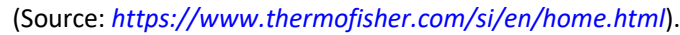

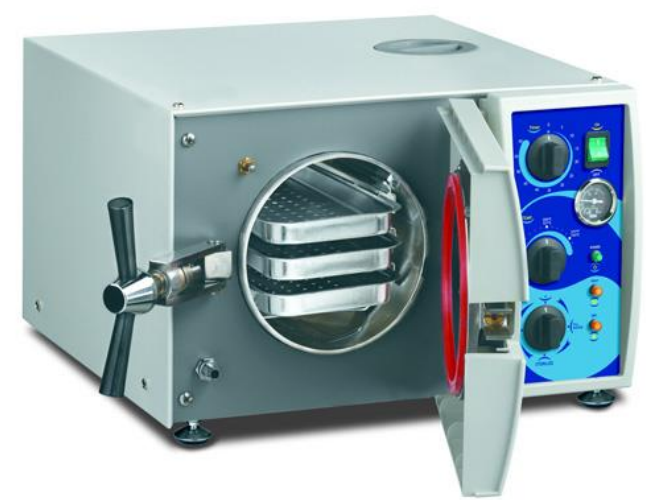

Figure 4: Autoclave.

(Source: $h$ ttp://www.quickmedical.com/tuttnauer-manual-medical-autoclave-sterilizer-valuklave-1730.html).

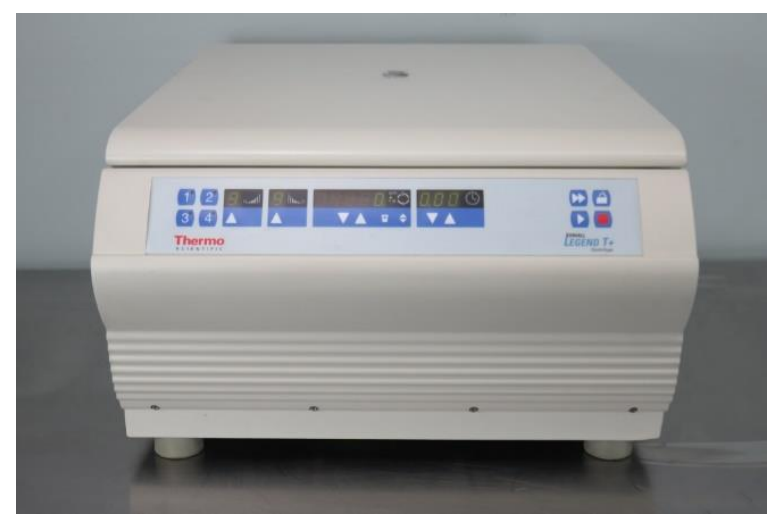

Figure 5: Centrifuge.

(Source: https://www.thermofisher.com/si/en/home.html). 
Primec, M., Langerholc, T.: BASIC MICROBIOLOGY: Instructions on Laboratory Exercises

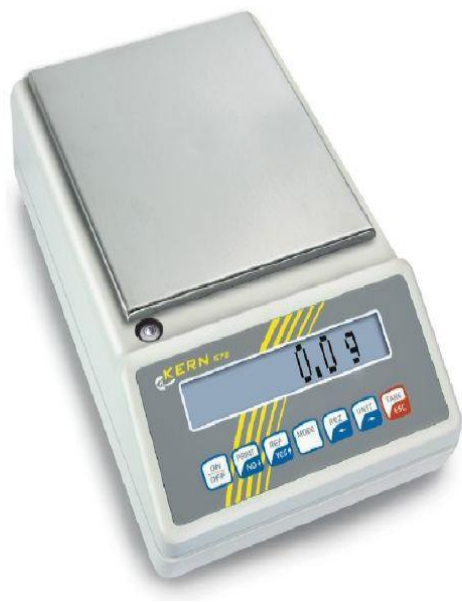

Figure 6: Analytical balance.

(Source: https://www.kern-sohn.com/en/).

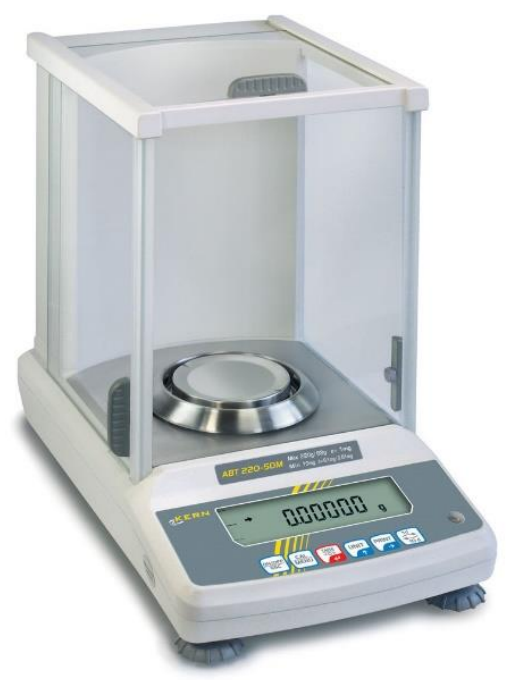

Figure 7: Precision balance.

(Source: https://www.kern-sohn.com/en/).

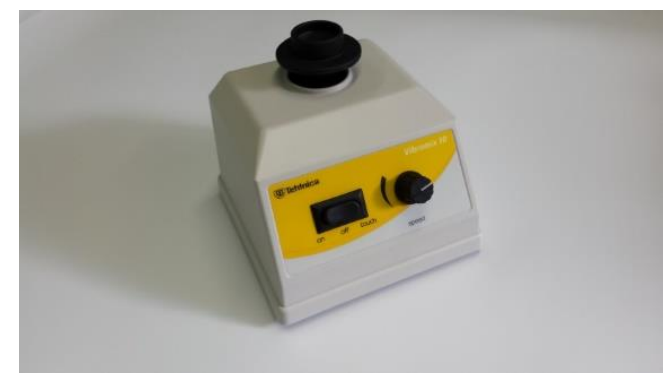

Figure 8: Vortex.

(Source: http://labs-sl.domel.com/products-en/VIBROMIX-10-Vortex-186/). 


\section{WORK IN A MICROBIOLOGY LABORATORY}

Successful experimental work in microbiology depends on the proper use of sterilized material and aseptic work with microorganisms. It is therefore very important to keep your hands clean: washing and afterwards disinfecting your hands before and after finishing the exercises is mandatory!

The growth of microorganisms can be controlled in different ways:

1. with aseptic work

2. with sterilisation

3. with pasteurisation

4. with disinfection

5. with antibiotics

\section{Aseptic work in a microbiology laboratory}

Most of the work performed in a microbiology laboratory demand handling with aseptic techniques. Microbiological working procedures (isolation of microorganisms from the sample, growth and final identification of microorganisms) need to be performed aseptically, i.e.:

a.) To avoid contaminating a sample with undesired microorganisms, as it may lead to incorrect results;

b.) To avoid spreading of the microorganisms, as it might cause an infection.

Use of aseptic techniques keeps the sterilized growth medium from being contaminated with microorganisms. It is therefore very important to keep working surfaces clean and desinfected, to work with sterilized equipment and close to a fire. Working in the radius cca. $30 \mathrm{~cm}$ around the fire is supposed to be aseptic.

Despite the guidelines of aseptic work are strictly followed, there is always a chance of culture and environmental contamination. 


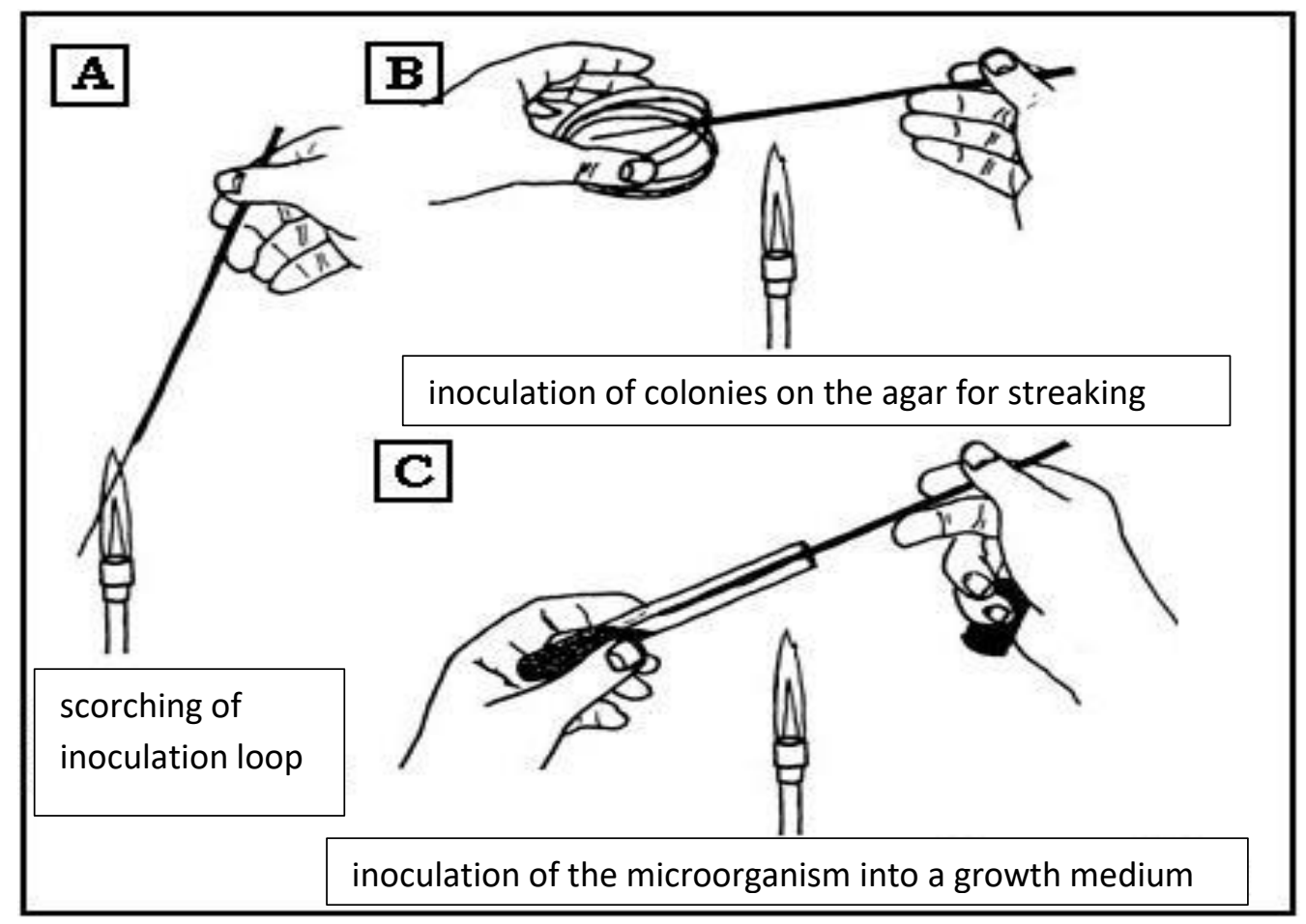

Figure 9: Aseptic technique work in front of a fire.

(Source: A courtesy of John Lindquist, Department of Bacteriology, University of Wisconsin - Madison (http://www.jlindquist.com/generalmicro/102aseptictechnique.htm/)).

\section{Sterilisation}

Sterilisation is a procedure, where all living microorganisms (also spores and viruses) are killed. It can be performed on different working surfaces, equipment, food, medicine or different kinds of growth medium by exposing them to physical, chemical or mechanical treatment. The choice of sterilisation method mostly depends on the nature of the material that needs to be sterilized and the convenience of the procedure. Based on the material to be sterilized, different kinds of sterilisations can be performed:

a) Dry sterilisation (glass and metal material):

- with fire (scorching)

- dry steriliser $\left(160-180^{\circ} \mathrm{C}, 120\right.$ to 150 minutes), less effective than steam sterilisation

- microvawe (glass, plastic, rubber: $1000 \mathrm{~W}, 3$ minutes) 


\section{b) Steam sterilisation:}

- Autoclave: plastic material, rubber, some growth media; at $1.3 \mathrm{bar}, 121^{\circ} \mathrm{C}$ $15-20$ minutes or $110^{\circ} \mathrm{C} 30$ minutes, destroys all living microorganisms and spores

- Koch pot: not hermetically closed - rubber, plastic material and thermally less resistant material; $100^{\circ} \mathrm{C}, 2$ hours

- Tindalisation or fractional sterilisation: substances, which are sensitive to higher temperatures (milk medium) are incubated at $100^{\circ} \mathrm{C}$ for $30 \mathrm{~min}$ (in order to kill all vegetative cells). Afterwards an incubation at $37^{\circ} \mathrm{C}$ is performed (the survived spores start to germinate). On the next day, all the vegetative cells that arise from the spores are killed, because they are incubated at $100^{\circ} \mathrm{C}$ - the whole procedure should be repeated at least one more time.

\section{c) Sterilisation with radiation}

- ultraviolet light radiation ( $240-280 \mathrm{~nm}$, very strong bactericidal effect on the surface)

- gamma radiation (PVC material)

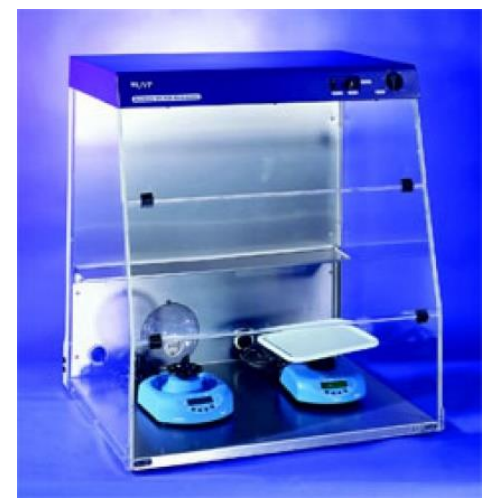

Figure 10: UV sterilization.

(Source:https://www.labsource.com/95-0367-01-bench-top-uv-sterilization-pcr-workstation.html).

\section{d) Sterilisation with ultrasound}

e) Sterilisation with gas (ethylenoxide, ozone, formalin, etc.) - toxic 


\section{f) Filtration}

- for substances (gas or liquid) that are sensitive to high temperatures (serum, antibiotics, media)

- bacteria $(0.22 \mu \mathrm{m}$ pore size filter removes all bacteria and spores, but not viruses); larger pore size filters $(0.45-0.65 \mu \mathrm{m})$ can be used to separate bacteria

- filtration can be performed by applying pressure or vacuum

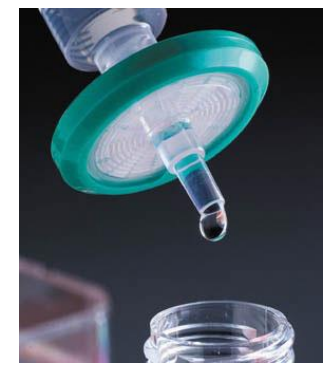

Figure 11: Filtration.

(Source: http://www.merckmillipore.com).

\section{Pasteurisation}

Pasteurisation: is a thermal procedure during food processing used to reduce the number of microorganisms, which may cause disease, food spoilage or even an undesired food fermentation. Thus, pasteurisation is important for disinfection of substances, which are sensitive to high temperature. Moreover, at the same time, enzymes in the food are deactivated by high temperature causing denaturation, ensuring a longer shelf life and preservation of food quality. The name pasteurisation comes from the name of Dr. Louis Pasteur, who used high temperature in order to control wine spoilage. It should be noted that pasteurisation is not a synonym for sterilisation as during the process, not all the microorganisms are killed. First attempts of pasteurisations were undertaken to destroy pathogenic bacteria in milk, such as Mycobacterium, Brucella, Salmonella, etc. 
Table 1: Types of pasteurisation in dairy industry.

\begin{tabular}{|c|c|c|c|}
\hline TYPE OF PASTEURISATION & ABBREVIATION & TEMPERATURE & TIME \\
\hline batch ("vat") & - & $63^{\circ} \mathrm{C}$ & 30 minutes \\
\hline High Temperature / Short Time & HTST & $72^{\circ} \mathrm{C}$ & 15 seconds \\
\hline Higher-Heat / Shorter Time & HHST & $89^{\circ} \mathrm{C}$ & 1 second \\
\hline Higher-Heat / Shorter Time & HHST & $90^{\circ} \mathrm{C}$ & 0.5 seconds \\
\hline Higher-Heat / Shorter Time & HHST & $94^{\circ} \mathrm{C}$ & 0.1 seconds \\
\hline Higher-Heat / Shorter Time & HHST & $96^{\circ} \mathrm{C}$ & 0.05 seconds \\
\hline Higher-Heat / Shorter Time & HHST & $100^{\circ} \mathrm{C}$ & 0.01 seconds \\
\hline ultra & UP (UHT) & $138^{\circ} \mathrm{C}$ & 2 seconds \\
\hline
\end{tabular}

(Source: $h t t p: / / w w w . i d f a . o r g)$. 


\section{Exercise 1: Sterilisation of different samples}

Before starting to work, disinfect your working place. Work in front of the opened fire at all times!

\section{Material and instruments:}

- 7 sterile test tubes $(15 \mathrm{~mL})$ with sterile nutrient broth $(10 \mathrm{~mL})$

- Referential microorganisms (Escherichia coli Nissle 1918) in saline solution $(0.9 \%)$

- incubator

- autoclave (steam steriliser)

- waterbath

- sterile $0.2 \mu \mathrm{m}$ filter

\section{Procedure:}

Put $0.1 \mathrm{~mL}$ of the prepared microorganism solution into sterile test tubes with broth from $2^{\text {nd }}$ till $7^{\text {th }}$.

Afterwards, proceed with the test tubes as follows bellow:

$1^{\text {st }}$ test tube: incubate the test tube with the sterile nutrient broth for 7 days at $30^{\circ} \mathrm{C}$ in an aerobic atmosphere (negative control);

$2^{\text {nd }}$ test tube: incubate the test tube with the nutrient broth and the microorganism solution for 7 days at $30^{\circ} \mathrm{C}$ in an aerobic atmosphere (positive control);

$3^{\text {rd }}$ test tube: autoclave the test tube with the nutrient broth and the microorganism solution at 1.3 bar, $121^{\circ} \mathrm{C}, 15 \mathrm{~min}$ and afterwards incubate it for 7 days at $30^{\circ} \mathrm{C}$ in an aerobic atmosphere;

$4^{\text {th }}$ test tube: pasteurise the test tube with the nutrient broth and the microorganism solution for $30 \mathrm{sec}$ in the water bath at $\underline{60^{\circ} \mathrm{C}}$ and afterwards incubate it for 7 days at $30^{\circ} \mathrm{C}$ in an aerobic atmosphere; 
$5^{\text {th }}$ test tube: warm up the test tube with the nutrient broth and the microorganism solution for $60 \mathrm{sec}$ in the water bath at $100^{\circ} \mathrm{C}$ and afterwards incubate it for 7 days at $30^{\circ} \mathrm{C}$ in an aerobic atmosphere;

$6^{\text {th }}$ test tube: incubate the test tube with the nutrient broth and the microorganism solution for $5 \mathrm{~min}$ in the water bath at $100^{\circ} \mathrm{C}$ and afterwards incubate it for 7 days at $30^{\circ} \mathrm{C}$ in an aerobic atmosphere;

$7^{\text {th }}$ test tube: filter the nutrient broth with microorganism solution through a sterile $\underline{0.2 \mu \mathrm{m}}$ filter into a new sterile test tube and incubate the test tube for 7 days at $30^{\circ} \mathrm{C}$ in an aerobic atmosphere.

Check out the test tubes for the potential growth of microorganisms (haziness) after the incubation period. Explain the results!

\section{Results:}

The growth of microorganisms in the nutrient broth after thermic, mechanical and physical pre-treatment of the samples:

\begin{tabular}{|l|l|l|}
\hline Test tube & Sample pre-treatment & Results \\
\hline $1^{\text {st }}$ & Negative control & \\
\hline $2^{\text {nd }}$ & Positive control & \\
\hline $3^{\text {rd }}$ & Steam sterilisation & \\
\hline $4^{\text {th }}$ & Pasteurisation at $60^{\circ} \mathrm{C}$ & \\
\hline $5^{\text {th }}$ & Incubation at $100^{\circ} \mathrm{C} 60 \mathrm{sec}$ & \\
\hline $6^{\text {th }}$ & Incubation at $100^{\circ} \mathrm{C} 5 \mathrm{~min}$ & \\
\hline $7^{\text {th }}$ & Filtration & \\
\hline
\end{tabular}




\section{Disinfection}

The use of chemical agents against microorganisms is very popular in everyday life. Disinfectants in microbiology laboratories are mostly used to disinfect microorganisms on the surfaces, equipment, instruments and glasses. Disinfection does not necessarily kill all microorganisms, especially resistant bacterial spores; it is less effective than sterilization. Moreover, disinfectants that are used to disinfect human beings are called antiseptics. THERE ARE SEVERAL PARAMETERS THAT SHOULD BE TAKEN INTO CONSIDERATION IN ORDER TO PERFORM A SUCCESSFUL DISINFECTION:

antimicrobial spectre of disinfectant

- optimal concentration of disinfectant

* optimal temperature of disinfectant

* optimal activity time of disinfectant

* microorganisms' environment.

Some of the most common used disinfectants are listed below:

- Chlorine (a powerful oxidant, works bactericidal; hypochlorite)

- Phenol (carbolic acid) and cresol (both organic disinfectants)

- Formaldehyde (gas - rooms, formalin - liquid disinfectant)

- Acids (reduce $\mathrm{pH}$ and denature proteins)

- Bases (hydrolyse proteins and carbohydrates)

- Alcohols (ethanol and propanol in the concentration of 70\%)

- Potassium permanganate (oxidant, first aid in hand and skin disinfection)

- Hydrogen peroxide

- lodine

- Detergents

Parameters that have an influence on the effectiveness of disinfectants:

- type and amount of microorganism (sensibility)

- concentration of disinfectant

- contact time of disinfectant 
- temperature of disinfectant solution

- type of material

- type of dirtiness on surfaces.

An ideal disinfectant should:

- have a broad anti-microbial spectrum

- be effective within its low concentration

- start working very quickly in a large range of $\mathrm{pH}$

- work in a presence of organic traces, cleaning fluids

- not be corrosive and hazardous to health

- be simple to use and should not foam

- have an unlimited date of expiry and should be cheap

- not have an uncomfortable odour and should not have any influence on the smell and taste of food

- quickly decompose and should be environmentally friendly

As there is no ideal disinfectant or cleaning fluid, the choice of parameters should be thoroughly considered in order to choose the most appropriate combination with the least negative characteristics. 


\section{Exercise 2: Minimal inhibitory concentration of antimicrobial substance}

The minimal inhibitory concentration (MIC) helps us to evaluate the antimicrobial activity of a chemical cleaning agent. MIC is the minimal concentration of a cleaning agent that is needed to inhibit the growth of certain microorganisms. MIC is not an absolute value, but it depends on the tested microorganism, the composition of the broth and on environmental factors such as temperature, $\mathrm{pH}$ and ventilation.

\section{Material and instruments:}

- 7 test sterile tubes $(15 \mathrm{~mL})$ with sterile nutrient broth $(4 \mathrm{~mL})$

- tested microorganisms (Escherichia coli Nissle 1918) in saline solution

- dilutions of $96 \%$ ethanol

\section{Procedure:}

1. Use the sterile nutrient broth ( $4 \mathrm{~mL}$ in 7 sterile test tubes $(15 \mathrm{~mL})$ ).

2. Aseptically mix $96 \%$ solution of ethanol and the corresponding volume of nutrient broth in test tubes in order to obtain the final concentration of ethanol: $30 \%, 14 \%, 7.8 \%, 4.1 \%, 2.0 \%$ in $1.0 \%$ in a total volume of $4 \mathrm{~mL}$.

3. Add $0.1 \mathrm{~mL}$ of the test microorganism aseptically.

4. After finishing, incubate the test tubes for 7 days at $30^{\circ} \mathrm{C}$.

Check out the test tubes for the potential growth of the microorganisms (haziness) after the incubation period and determine the MIC of ethanol.

\section{Results:}

The growth of microorganisms in nutrient broth with different \% of ethanol concentration.

\begin{tabular}{|c|c|c|c|c|c|c|c|}
\hline \% ethanol & 70 & 30 & 14 & 7.8 & 4.1 & 2.0 & 1.0 \\
\hline $\begin{array}{c}\mathrm{mL} \text { of } 96 \% \\
\text { ethanol }\end{array}$ & 2.92 & 1.25 & 0.58 & 0.325 & 0.17 & 0.083 & 0.042 \\
\hline growth (Y/N) & & & & & & & \\
\hline
\end{tabular}


Exercise 3: Comparison of antimicrobial effects of different hand disinfectants

\section{Material and instruments:}

- 3 nutrient agar plates

- hand disinfectants (3 different types)

- sterile plastic inoculation loop

- swab

- saline solution

\section{Procedure:}

1. Divide the bottom of the nutrient agar into two equal parts.

2. Take a swab from your unwashed hand and spread it onto a half of the agar plate. Wash the same hand with soap and leave it until it dries up. Take a swab from the washed hand and spread it onto the other half of the agar plate. Repeat the exact procedure on the other two plates.

3. Take one agar plate for each disinfectant. Put a small amount of one disinfectant (apply with a pipette or inoculation loop) on both parts of the agar plate. Try to apply it in the middle of both parts of the agar plate. Repeat the procedure with the other two plates.

3. Incubate the agar plates at $37^{\circ} \mathrm{C}$ for $24-48$ hours and measure the inhibition zone around each disinfectant with the help of a ruler.

4. Evaluate and compare the results with the other groups. Do the inhibition zones of the same disinfectant differ from each other?

\section{Results:}

Measure the inhibition zones and compare the results with other groups.

\begin{tabular}{|c|c|}
\hline Disinfectant & Inhibition zones (mm) \\
\hline & \\
\hline & \\
\hline & \\
\hline
\end{tabular}




\section{Antibiotics and their effect on microorganisms (antibiogram)}

A microbiological diagnosis of a disease consists of two basic procedures: isolation (detection) of pathogens that caused the disease and determination of a proper antibiotic in case the agent is a bacteria. It is well known that many antibiotics lose their activity due to the resistance that originates from mutations in bacteria.

Antibiograms are commonly used to determine bacterial sensitivity to antibiotics. They can be performed in different ways, depending on whether we want to test the effectiveness of a tested antibiotic in different concentrations or to test the sensitivity of a particular bacterial strain to different antibiotics.

\section{A.) Diffusion antibiogram}

A diffusion antibiogram is a simple and quick test that helps to determine the sensitivity of a certain bacterial strain to different antibiotics. Procedure:

- Spread enough bacterial solution onto an agar plate in order to obtain a confluent growth.

- Put different antibiotic-soaked discs onto the agar plate.

- Incubate the agar plate to allow bacteria to grow.

The antibiotic diffuses into the agar and consequently, a concentration gradient around the disc is formed. If the bacterial strain is sensitive to the antibiotic, it will not grow closer from a specific distance from the disc (inhibition zone). With regard to the diameter of the zone (in $\mathrm{mm}$ ), sensitivity of the bacterial strain to the tested antibiotic can be interpreted as sensitive, intermediate or resistant. The inhibition zone does not depend only on the antimicrobial potency of an antibiotic, but also on other factors, such as the agar thickness. Therefore, it is important that the method is standardized in order to accumulate comparable results in a given period of time.

When interpreting an antibiogram, the growth of tiny colonies in the inhibition zone should be taken into consideration. They are so called resistant mutants. Such an antibiotic should not be considered for therapeutic purposes, as its use can lead to a selection of resistant strains and consequently to malpractice. 


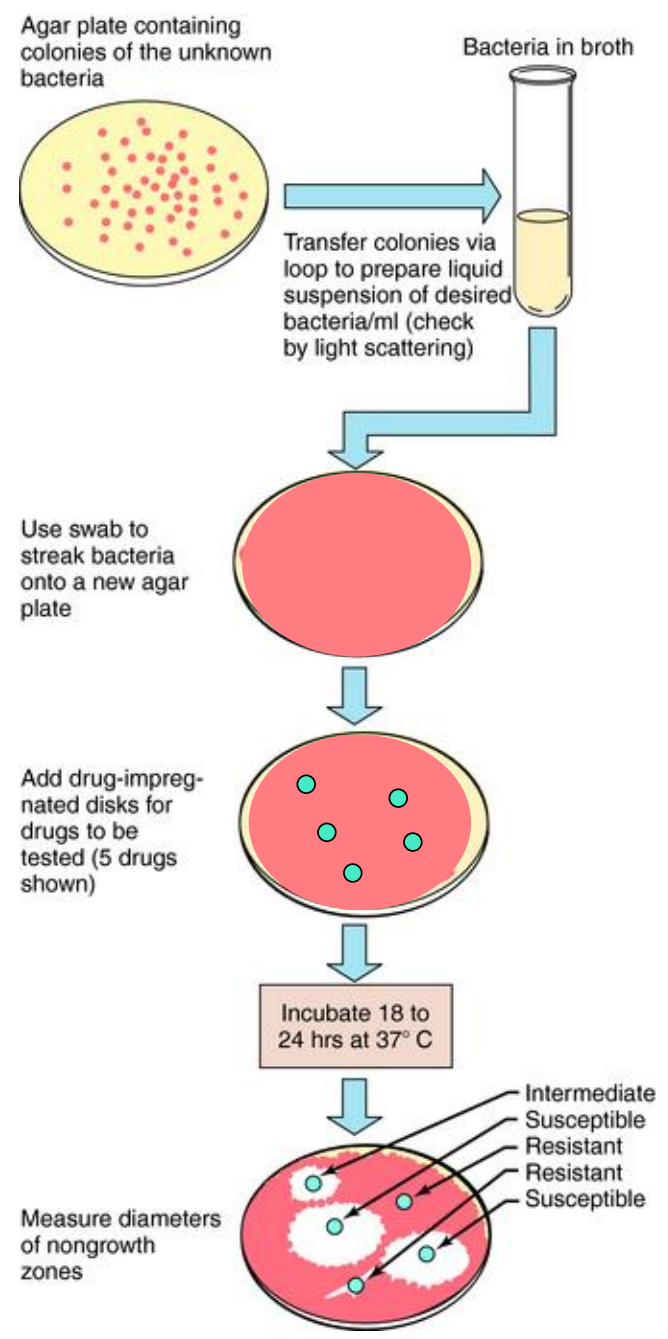

Figure 12: Antibiogram of a diffusion principle.

(Modificated source: A courtesy of http://clinicalgate.com/principles-of-antimicrobial-use).

\section{B.) Dilution antibiogram}

Dilution antibiogram is a quantitative test, where a minimal inhibitory concentration (MIC; concentration of antibiotic that inhibits the growth of bacteria) and minimal bactericidal concentration (MBC; antibiotic concentration that kills bacteria) can be determined. MIC is evaluated based on the turbidity of the bacterial solution in the test tube, whereas MBC is evaluated based on the bacterial growth on the agar plate. 
A

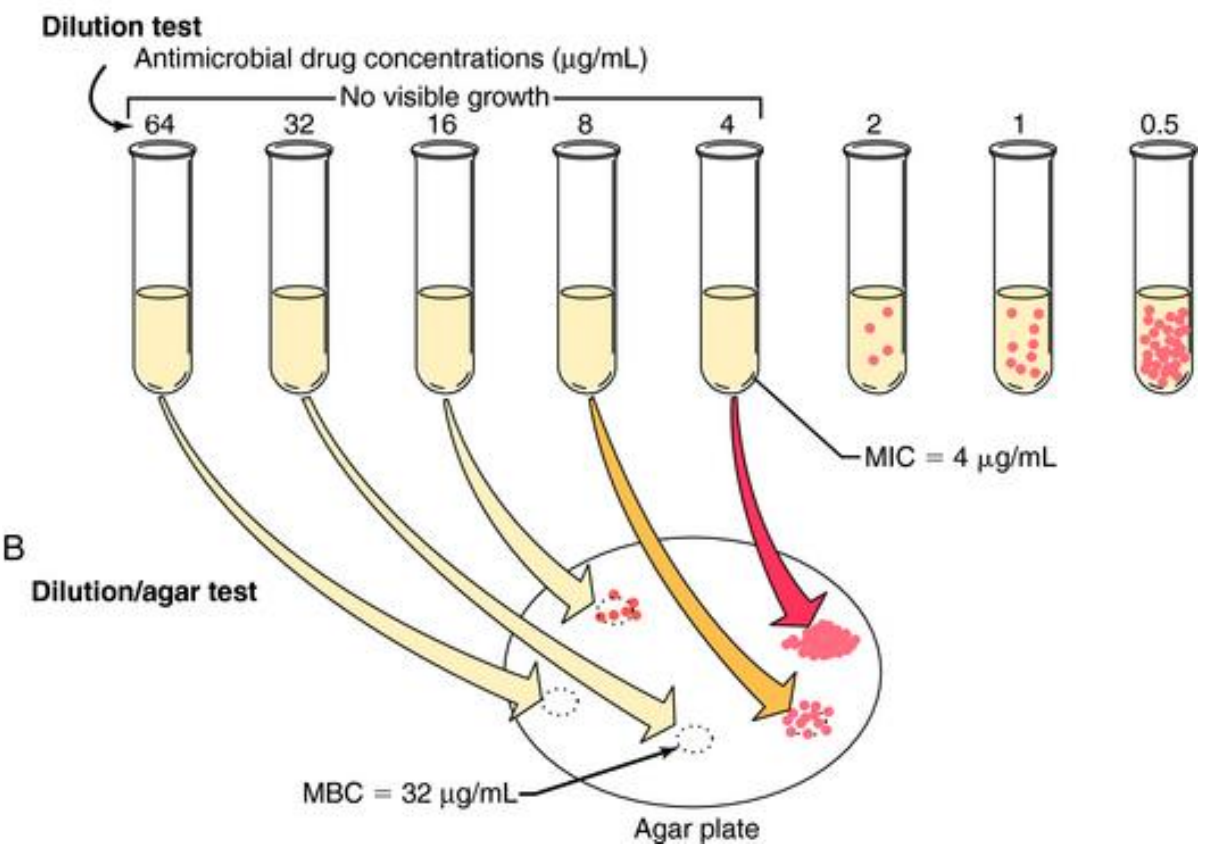

Figure 13: Antibiogram of a dilution principle.

(Source: A courtesy of http://clinicalgate.com/principles-of-antimicrobial-use/).

\section{C.) Incorporated antibiogram}

An incorporated antibiogram is based on agar with a selective supplement (antibiotic). It is used to select fastidious bacteria that grow very slowly (Mycobacterium tuberculosis), or in order to determine the efect of one antibiotic on different bacterial strains. 


\section{Exercise 4: Diffusion antibiogram}

\section{Material and instruments:}

- Nutrient agar plates with Escherichia coli or Staphylococcus epidermidis

- nutrient agar plates

- sterile test tube $(15 \mathrm{~mL})$ with $3 \mathrm{~mL}$ of sterile saline solution

- Drigalski spatula

- antibiotic discs

- forceps

- burner

- incubator

\section{Procedure:}

1. Transfer a loop of biomass from the agar plate with grown bacterial culture into the test tube with saline solution. Mix the material with the solution (resuspension).

2. Vortex the bacterial solution in order to obtain a homogeneous suspension.

3. Transfer $0.1 \mathrm{~mL}$ of bacterial suspension onto a sterile nutrient agar and spread it carefully with the help of the Drigalski spatula.

4. Take a proper antibiotic disc with the help of fire-sterilized forceps and put it onto an agar plate.

5. Cover the agar plate and leave it $\mathbf{1 5} \mathrm{min}$ at room temperature in order for the disc to defund into the agar.

6. Incubate the agar plates for $24 \mathrm{~h}$ at $37^{\circ} \mathrm{C}$.

7. Measure the inhibition zone around the antibiotic disc with the help of a ruler.

8. Interpret the microorganism sensitivity to the tested antibiotic following the manufacturer's instructions. 


\section{Results:}

Measure the inhibition zones and define the microorganism sensitivity to the tested antibiotics.

Microorganism culture:

\begin{tabular}{|l|c|c|}
\hline Antibiotic & $\begin{array}{c}\text { Diameter of the } \\
\text { inhibition zone }(\mathrm{mm})\end{array}$ & Interpretation \\
\hline & & \\
\hline & & \\
\hline & & \\
\hline & & \\
\hline
\end{tabular}

Table 2: Table of sensitivity tests of antibiotics BD BBL Sensi-Disc.

\begin{tabular}{|c|c|c|c|c|c|}
\hline \multirow{2}{*}{ Antibiotic } & \multirow[b]{2}{*}{ Code } & \multirow[b]{2}{*}{$\begin{array}{l}\text { Amount } \\
\text { (pro disc) }\end{array}$} & \multicolumn{3}{|c|}{ Interpretation of the inhibition zones (mm) } \\
\hline & & & Resistant & Intermediate & Sensitive \\
\hline Ampicillin & $\begin{array}{l}\text { SAM- } \\
20\end{array}$ & $10 / 10 \mu \mathrm{g}$ & $\leq 11$ & $12-14$ & $\geq 15$ \\
\hline Clindamycin & CC-2 & $2 \mu g$ & $\leq 14$ & $15-20$ & $\geq 20$ \\
\hline Erythromycin & $\mathrm{E}-15$ & $15 \mu \mathrm{g}$ & $\leq 13$ & $14-22$ & $\geq 23$ \\
\hline Gentamicin & $\begin{array}{l}\text { GM- } \\
10\end{array}$ & $10 \mu \mathrm{g}$ & $\leq 12$ & $13-14$ & $\geq 15$ \\
\hline Oxacillin & OX-1 & $1 \mu \mathrm{g}$ & $\leq 17$ & & $\geq 18$ \\
\hline Penicillin & $\mathrm{P}-10$ & $10 \mathrm{U}$ & $\leq 28$ & & $\geq 29$ \\
\hline Trimethoprim/Sulfamethoxazole & SXT & $1,25 \mu \mathrm{g}$ & $\leq 10$ & $11-15$ & $\geq 16$ \\
\hline
\end{tabular}




\section{ISOLATION OF A PURE CULTURE - IDENTIFICATION OF BACTERIA}

Environmental samples consist of many microorganisms, having different morphological and physiological characteristics. A mixed culture consists of more than one bacterial strain and its characteristics cannot be attributed to only one bacterial strain in a culture. Bacterial characteristics can therefore be studied and determined only if a specific bacterial strain is properly isolated in a culture. Therefore, a pure culture consists of only one type of bacteria and the type of bacteria determines the characteristics of a culture itself. Different methods of bacterial isolation from mixed cultures are known.

\section{Culture purity and isolation of a pure culture}

Each culture needs to be tested for purity. The purity of bacterial suspensions (in liquid media) can be evaluated under a microscope. A pure bacterial suspension consists of cells of the same shape and morphology. If a bacterial suspension is pleomorphic i.e. consists of different cells or cells that are very much alike and very hard to distinguish from one another under a microscope, an inoculation onto a solid medium (agar) is recommended. That way, colonies that grow on the agar can be observed and morphologically differentiated between each other with a naked eye. If only one type of a colony is determined, a presumably pure culture is obtained.

\section{Terminology:}

Colony: is a unit of cells that have grown after a period of incubation time from one initial bacterial cell. Bacteria in a colony are therefore clones of the same parental bacterial cell.

Strain: further culturing of one cell offspring leads to the growth of a specific strain.

Culture: consists of growth medium (liquid - broth or solid - agar) and bacteria. 
- Pure culture: consists of bacteria of the same species.

- Mixed culture: consists of bacteria of different species.

- Primary culture: the very first culture that has grown on a growth medium after inoculation from a sample.

- Subculture: is obtained by inoculating the colonies from one growth medium onto another.

Microorganism isolation from sample materials can be performed in two different ways:

\section{Direct method}

It consists of a sample resuspension and dilution. The suspension is evaluated under the microscope and one cell is picked and transferred into a fresh growth medium (a suitable method for isolation of moulds).

\section{Indirect method}

After obtaining single colonies upon agar plating of mixed culture, the desired colony is picked and subcultured to obtain a pure culture.

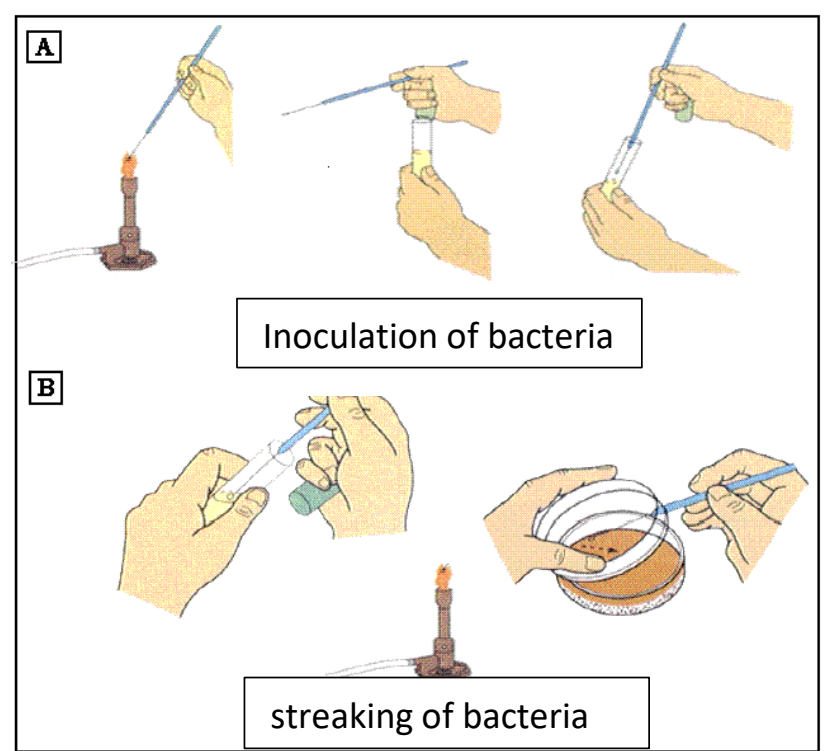

Figure 14: (A) Inoculation of bacteria into broth growth medium; (B) Transfer of bacteria onto a solid agar for streaking.

(Source: A courtesy of John Lindquist, Department (http://www.jlindquist.com/generalmicro/102aseptictechnique.html).

of Bacteriology, University of Wisconsin - Madison 
To obtain a single, isolated colony, a special dilutional streaking technique can be performed (see bellow).

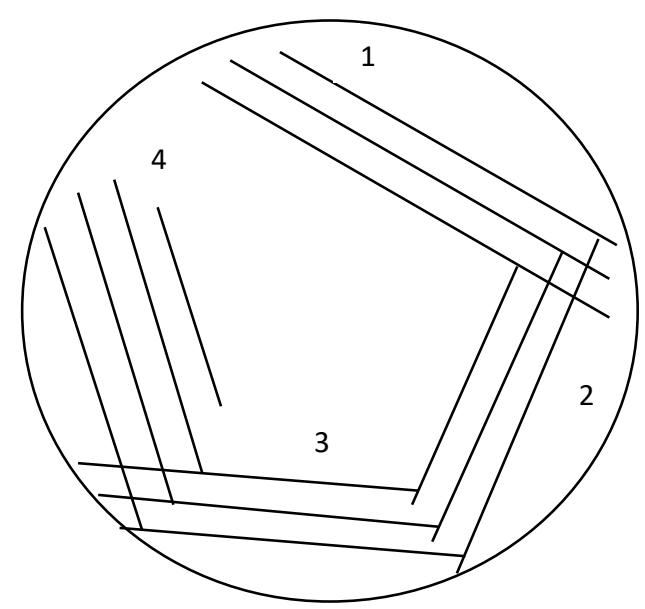

Figure 15: Dilutional streaking technique. (Source: own).

\section{Identification (determination) of bacteria}

Identification means classification of a strain as a spieces or genus regarding its specific characteristics. Morphological, physiological and biochemical characteristics are the main characteristics that contribute to the bacterial identification. Neverthelles, the most reliable bacterial classification is based on $16 \mathrm{~S}$ rRNA gene sequencing and alignment of the obtained sequences to those already present in online databases. Sequence similarity of more than $97 \%$ indicate the same species.

\section{Morphological characteristics}

\section{- Macromorphological characteristics}

On the agar medium, colonies differ from each other in regard to:

- colony shape - round, irregular, philamentous, rhizoid etc.,

- edge shape - smooth, rough, serrated, with invaginations etc., 
- consistency - fragile, hard, greasy, mucous (M colony) etc.,

- vertical section - flat, lifted (proud), convex etc.,

- size - in mm of diameter

- surface - smooth, rough, wet, dry, wrinkled etc.,

- colour - transparent, white, violet, fluorescent etc.,

- time of growth

- pigmentation, which colors the colony or agar.

In regard to the edge and surface, the colony is reffered to as:

- Colony S (= smooth): flat edge and shiny surface.

- Colony R (= rough): serrated edge and opaque surface.

- Colony I (= intermedium): between S and R.

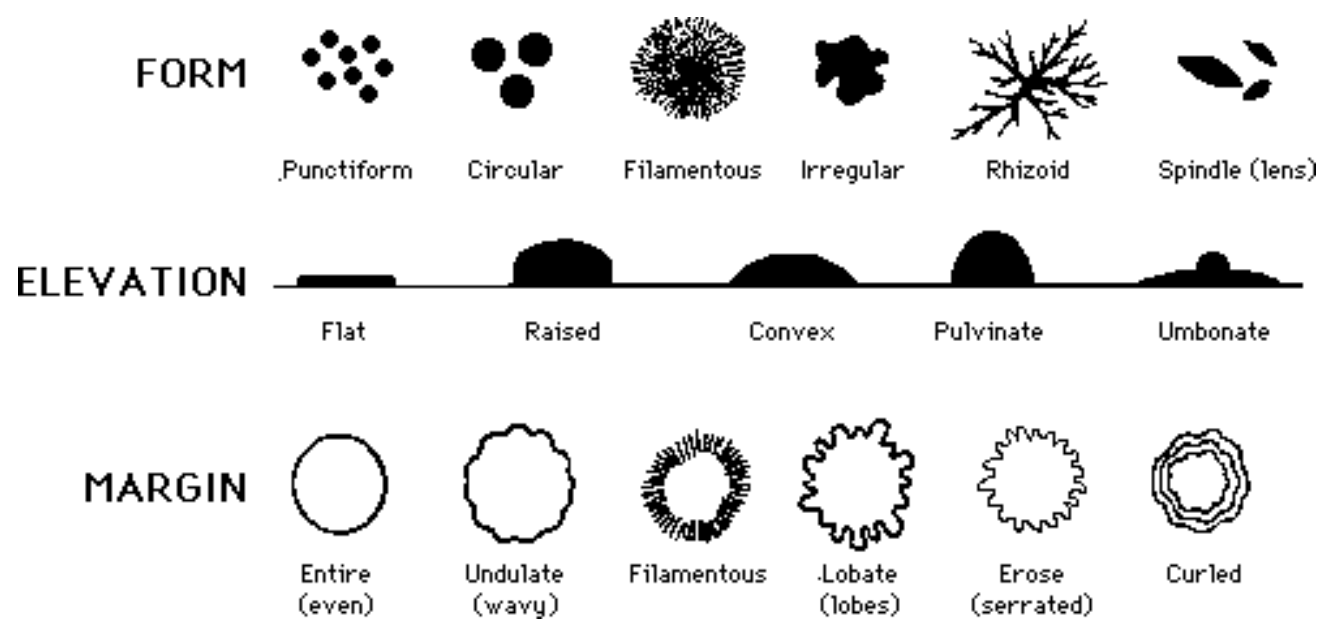

Figure 16: Basic shapes of bacterial colonies.

(Source: Talaro \& Talaro, Foundations in microbiology, 3e, Copyright 1999, a permission of The MacGraw-Hill Companies, Inc. (https://www.pinterest.com/pin/373728469052897686/).

In liquid medium (broth) bacterial strains differ from each other in regard to:

- formation of haziness, sediment and film,

- formation of gas,

- colour of medium and

- colour of colonies. 


\section{- Micromorphological characteristics - cell morphology}

- shape - cocci, bacilli, spirilli, vibrio etc.,

- size,

- presence of a capsule,

- spore shape in the case of sporulation,

\section{- Gram staining.}

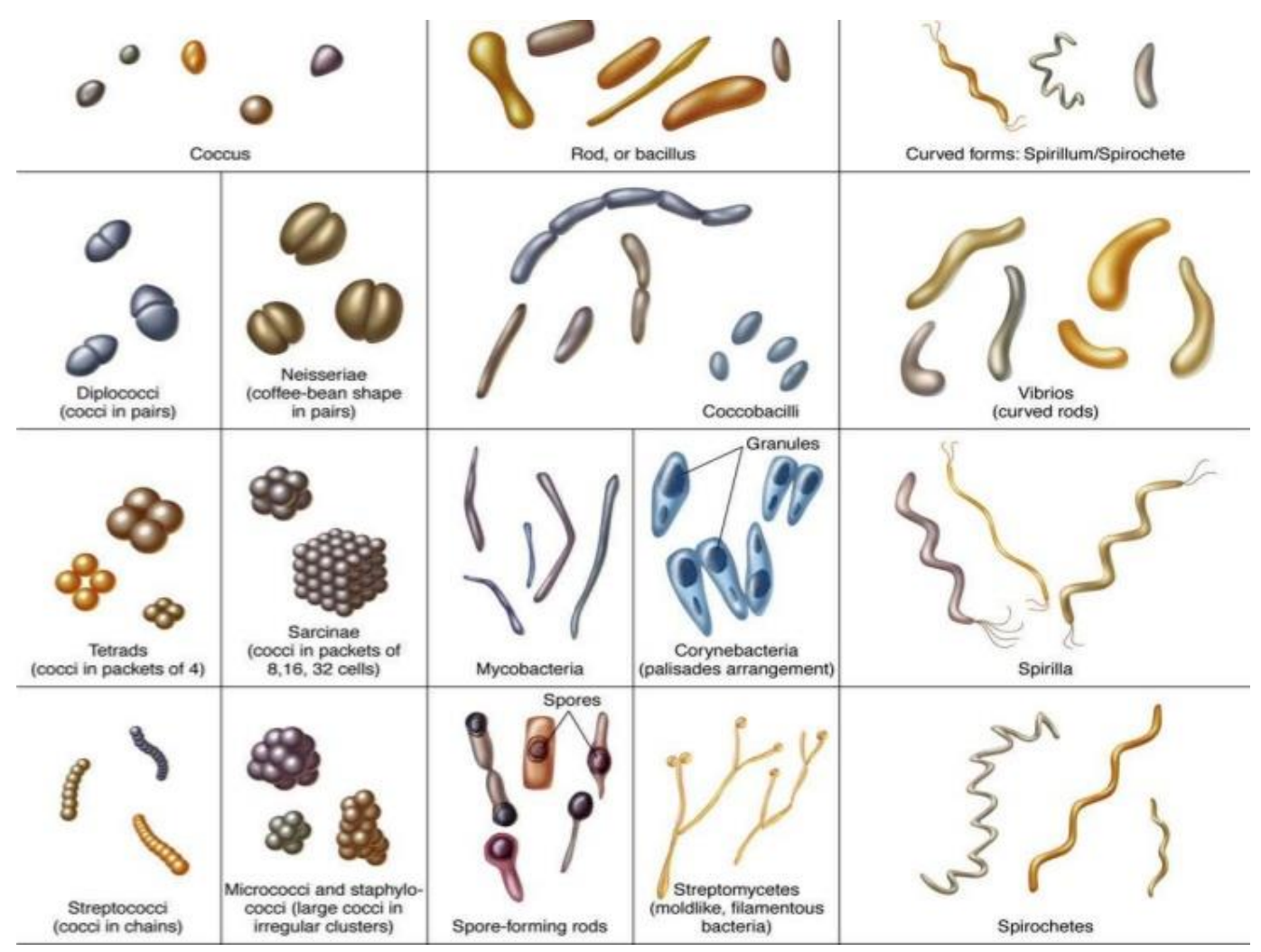

Figure 17: Basic micromorphological characteristics of bacteria.

(Source: Talaro \& Talaro, Foundations in microbiology, 3e, Copyright 1999, a permission of The MacGraw-Hill Companies, Inc. (https://www.pinterest.com/pin/373728469052897686/). 


\section{Physiological characteristics}

With regard to the need of oxygen, microorganisms are divided into several groups:

- Strict aerobes - grow only in normal atmospheric conditions (oxygen presence).

- Strict anaerobes - grow in atmosphere without oxygen.

- Facultative anaerobes - grow in aerobic and anaerobic conditions.

- Aerotolerant microorganisms - anaerobic microbes that grow in tolerably small amounts of oxygen.

- Microaerophiles - grow exclusively in an atmosphere with reduced amount of oxygen $\left(5-10 \% \mathrm{CO}_{2}\right)$.

\section{Biochemical characteristics}

Microorganisms can grow using different carbohydrates, alcohols, proteins, nitrates as primary catabolic molecules for their proper physiological function.

Moreover, they have a possibility of different substrate decomposition carbohydrates, starch, proteins ad fats. Metabolic decomposition of these nutrients can be oxidative (with oxygen) or fermentative (without oxygen). 


\section{Exercise 6: Extent of microorganisms in the environment}

The aim of this exercise is to learn about the general extent of microorganisms in our environment.

We will try to show the presence and the diversity of microorganisms in five different environments: air, water, soil, skin and plants, by describing their macromorphological characteristics.

\section{Material and instruments:}

- sterile nutrient agars

- sterile plastic inoculation loops

- pipettes

- water; soil; air, skin; green parts of a plant

\section{Procedure:}

Water environment: take a sample of water with the help of the inoculation loop and put it onto a sterile nutrient agar.

Soil environment: prepare a soil suspension (10 g of soil into $90 \mathrm{~mL}$ of saline solution in an erlenmayer glass) and $\mathrm{mix}$ it for at least $5 \mathrm{~min}$. Take a sample of soil suspension with the help of the inoculation loop and put it onto a sterile nutrient agar.

Skin: uncover an agar plate and touch the agar with your finger. Cover the agar plate quickly afterwards.

Plants: use the green parts or the plant. Spread the plant over the whole agar plate.

$\underline{\text { Air: }}$ uncover an agar plate and leave it uncovered for $15 \mathrm{~min}$.

- Incubate all agar plates aerobically for 1 week, at $30^{\circ} \mathrm{C}$.

- Clean the working places and your hands (disinfection) before going out of the laboratory. 
After 1 week of incubation, evaluate microorganism growth on each agar plate.

\section{Water}

- Colour of colonies:

- Shape of colonies:

- Margin of colonies:

- Surface of colonies:

- Profile of colonies:

- Consistence of colonies:

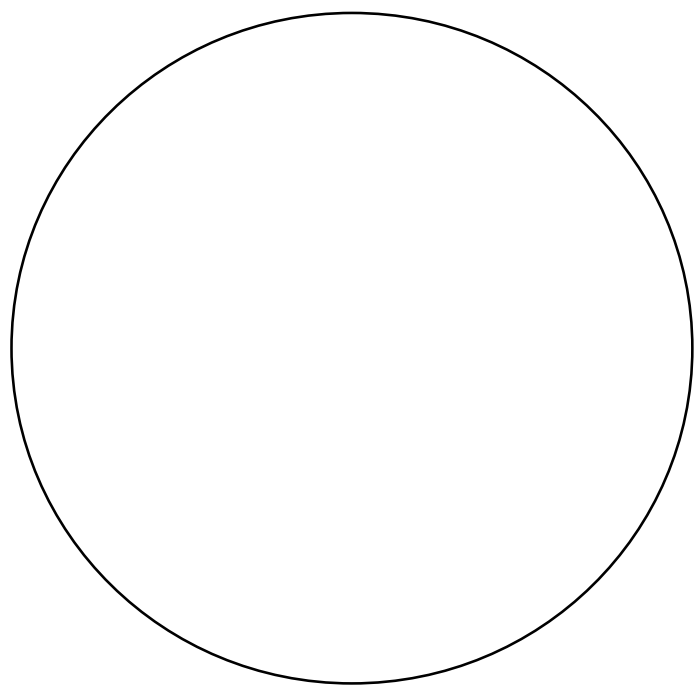

Soil

- Colour of colonies:

- Shape of colonies:

- Margin of colonies:

- Surface of colonies:

- Profile of colonies:

- Consistence of colonies:

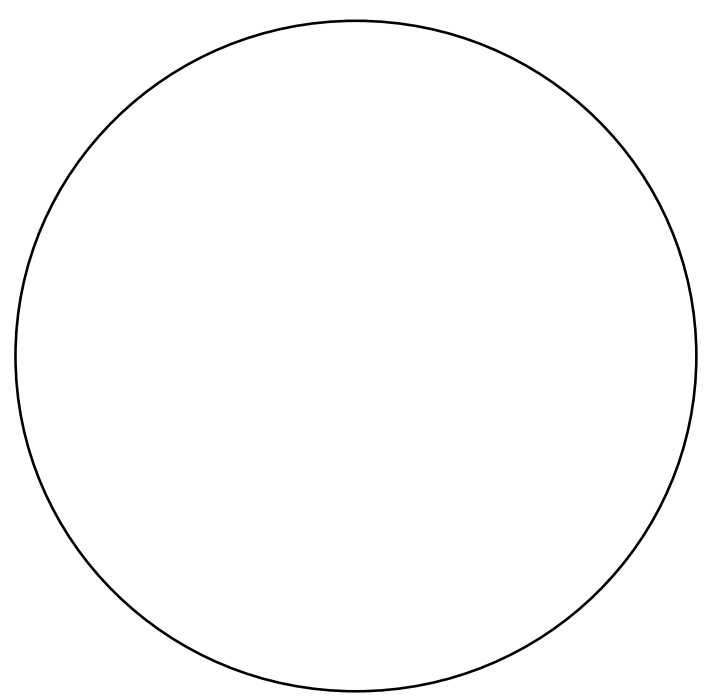

Skin

- Colour of colonies:

- Shape of colonies:

- Margin of colonies:

- Surface of colonies:

- Profile of colonies:

- Consistence of colonies:

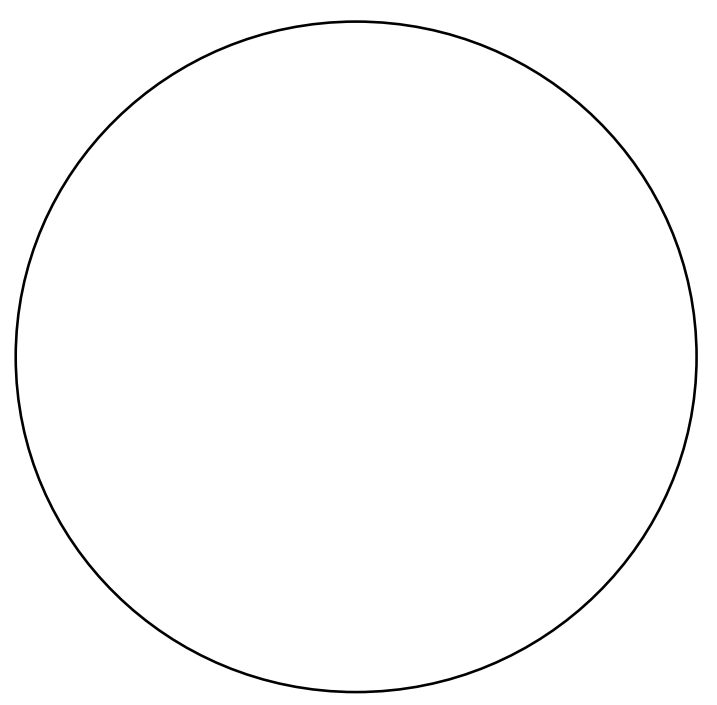


Plant

- Colour of colonies:

- Shape of colonies:

- Margin of colonies:

- Surface of colonies:

- Profile of colonies:

- Consistence of colonies:

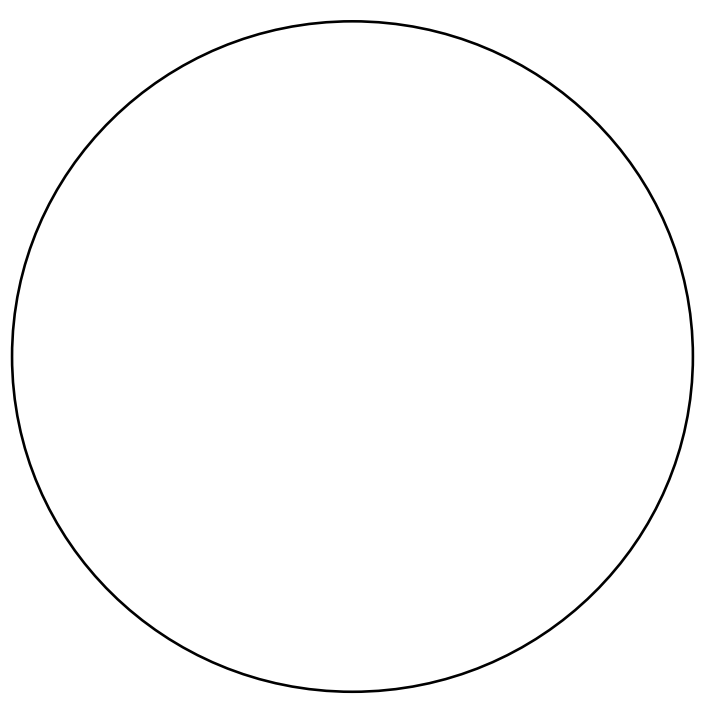

Air

- Colour of colonies:

- Shape of colonies:

- Margin of colonies:

- Surface of colonies:

- Profile of colonies:

- Consistence of colonies:

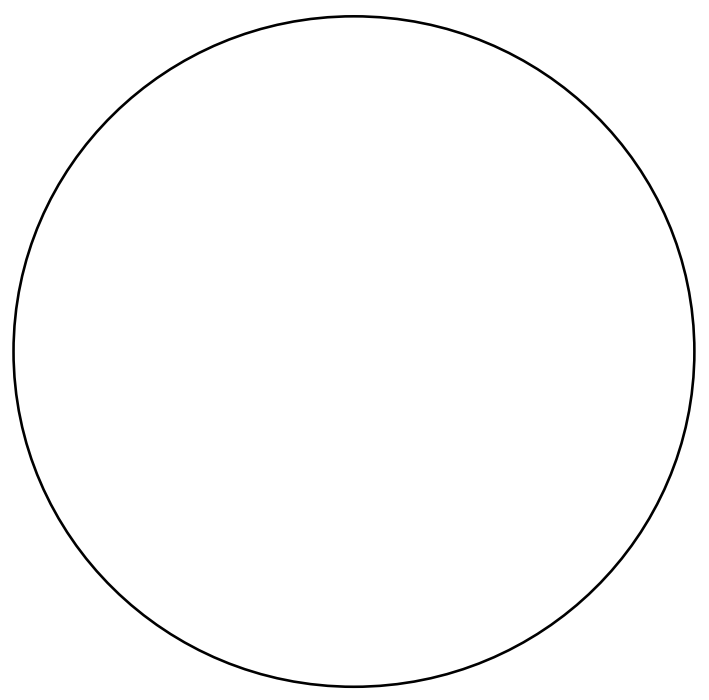




\section{MICROSCOPE AND MICROSCOPY TECHNIQUES}

A microscope is an important instrument in a microbiology laboratory. Optical and electrone microscopes are by far the most used in microbiology.

\section{Optical microscope}

Optical microscopes are commonly used for the observation of different microorganisms. It consists of mechanical and optical parts.

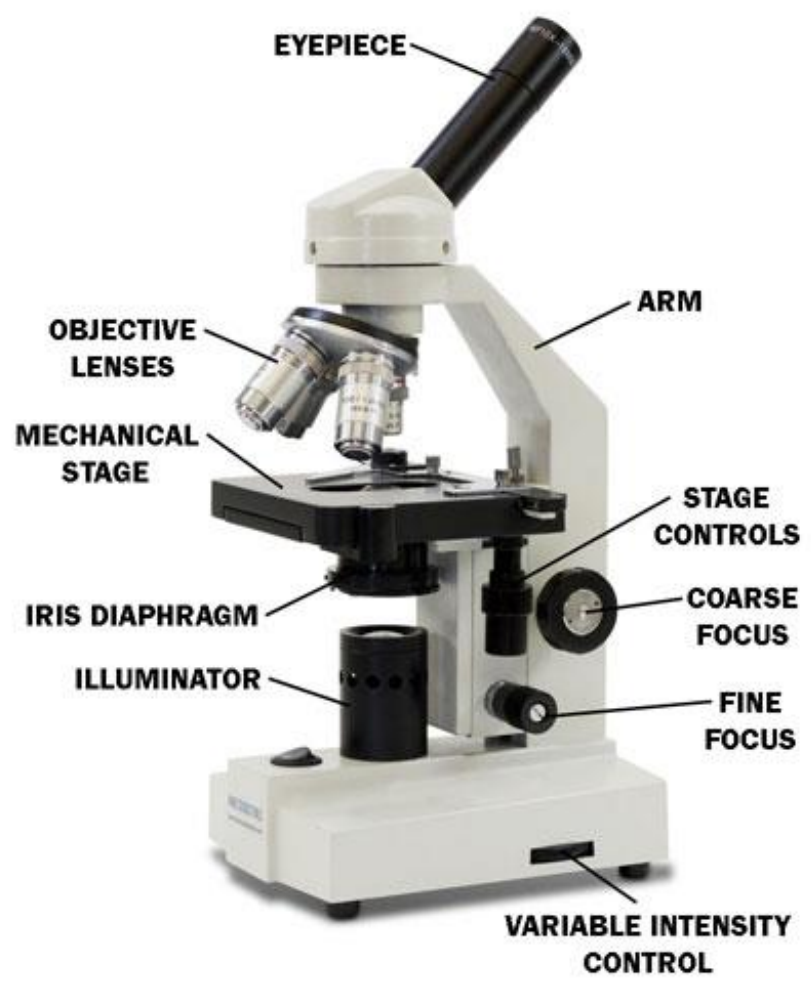

Figure 18: Optical microscope.

(Source: $h t t p: / / w w w . f r e e i n f o s o c i e t y . c o m / m e d i a . p h p ? i d=1250$ ).

The mechanical microscope parts are: base, arm, stage, tubus (eyepiece lens and objective lenses) and two focuses (fine and coarse).

The optical microscope parts are: eyepiece lens and objective lenses, condenser, diaphragm, filter and a source of light. The substance beetwen the objective lens and the microscopic slide defines whether a dry objective lens (substance is air) or an immersion objective lens (substance is immersion oil) is used. 
The overall microscope magnification is determined by multiplying an objective with an eyepiece magnification; a combination of $4 \times$ objective and a $10 x$ eyepiece produces an image that is 40 times the size of the object. The light system consists of light, condenser and diaphragm. The condenser function is to focus the light beam onto the object. The diaphragm regulates the proportion of the light beam on the object. Depending on the objective lense and the condenser type, different microscopy techniques are known:

- in a light visible field

- in a dark visible field Objects are illuminated, background is dark; suitable for microscopy of live microorganisms.

- with phase contrast Objects are, depending on the type of the phase contrast plate, dark with a light edge, or light with a dark edge; suitable for microscopy of live microorganisms.

- with fluorescent microscope

Used to observe fluorescent objects or objects that have been dyed with different kinds of fluorescent dyes.

\section{Electron microscope}

An electron microscope is merely used in viral diagnostics and different scientific research fields. It is very sensitive and the object's size is observed within the range of $0.001 \mu \mathrm{m}\left(\mathrm{nm}, 10^{-9}\right)$. Instead of a light beam and lenses, electrons and electromagnets are used, respectively. 
Table 3: Comparison between different types of microscopy.

\begin{tabular}{|c|c|c|c|}
\hline TYPE OF MICROSCOPY: & MAGNIFICATION: & IMAGE OF A SAMPLE: & APPLICABILITY: \\
\hline Light visible field & $1000-2000$ & Coloured or trasparent & $\begin{array}{c}\text { Morphological } \\
\text { analyses, bacteria, } \\
\text { yeast, algae, protozoa } \\
\text { analyses }\end{array}$ \\
\hline Dark visible field & $1000-2000$ & Usually not coloured & $\begin{array}{c}\text { Analysis of } \\
\text { microorganisms with } \\
\text { special morphological } \\
\text { characteristics } \\
\text { (Spirochaete) }\end{array}$ \\
\hline Phase contrast & $1000-2000$ & $\begin{array}{c}\text { Coloured, depending } \\
\text { on the type of } \\
\text { fluorochrome }\end{array}$ & $\begin{array}{c}\text { Detection of different } \\
\text { kind of microorganisms }\end{array}$ \\
\hline Electron & \multirow{2}{*}{$2000-2000$} & $\begin{array}{c}\text { Different degrees of } \\
\text { dark contrasting }\end{array}$ & $\begin{array}{c}\text { Analysis of cell } \\
\text { structure in live cells } \\
\text { (moulds, algae, } \\
\text { protozoa and some } \\
\text { bacteria) }\end{array}$ \\
\hline & $\begin{array}{c}\text { Light on a fluorescent } \\
\text { screen }\end{array}$ & $\begin{array}{c}\text { Analysis of very small } \\
\text { objects (viruses); } \\
\text { Analysis of microbial } \\
\text { cell ultrastructure }\end{array}$ \\
\hline
\end{tabular}

\section{Rules of microscopy}

Before using the microscope, certain rules have to be taken into consideration:

- Make sure that the object lies on the correct side of the microscopic slide!

- Regulate the source of light, lift up the condenser and open the diaphragm.

- Important! Start microscoping with the smallest power objective lens.

- Use the coarse focus to move the objective lens closer to the microscopic slide (watch out not to damage it) till the image appearance.

- Use the fine focus to sharpen the image. 
Rules for microscopy with an immersion objective lens:

1. Before using the immersion objective lens, start microscoping as described previously.

2. Put a drop of immersion oil on the object glass.

3. Carefully, with the help of a coarse focus, move the immersion objective lens towards the object glass till it touches the oil drop.

4. Use the fine course to sharpen the image.

5. After finishing, clean the objective lens thoroughly with ethanol.

\section{Origin of specimens for the mounting technique}

Specimens or samples may originate from a microbial culture or biological material. Bacteria, moulds and yeasts are cultured in different mediums (in broth or on agar); viruses need live cells for living.

\section{Preparation of specimens on microscopic slides (mounting)}

Specimens are prepared on the object glasses (slides), which have to be clean. If necessary, a thorough cleaning of the dust and dirt should be performed, using alcohol or some fat emulgators. Generally for bacteria, yeast and mould cells observation, two kinds of mounts are known: wet and prepared (fixed).

\section{Wet mount}

Wet mounts are prepared to watch and determine live, non-stained microorganisms (mostly bacteria), especially their movement, approximate size, shape and arrangement. Some bacteria move with flagellous, others with periplasmatic (axial) fibrillas (Spirochetes).

The preparation of wet mount is performed by dropping a suspension or liquid bacteria broth on the object glass and cover it with the deck glass.

Another technique of mounting helps to evaluate live microorganisms: their movement, sporulation and multiplication. Preparation of such mounts needs a special object glass with a cavity in the middle (concavity slide or cavity slide). A 
drop of bacterial suspension is put on the deck glass. A small amount of Vaseline is spread on the cavity edge of the object glass. The object glass is turned upside down on the deck glass. Finally, both are turned back and as a result, the bacterial drop hangs free in the cavity.

\section{Prepared (fixed) mount}

Mostly, microorganisms are transparent and colourless. Furthermore, because of their small size, they are very hard to see by using an optic microscope. Staining of microorganisms allows a direct evaluation of their size, shape, inner and outer structure (capsule, spores, flagella, etc.).

a) Prepared mounts from bacterial broth suspensions are prepared by putting a drop of the suspension on the object glass and by spreading it with the inoculation loop.

b) Prepared mounts from bacterial agar cultures are prepared by putting a drop of saline solution on an object glass, resuspending a tiny amount of microbes in it and by spreading it over the whole object glass.

c) Prepared mounts from biological material can originate from:

- animal / human / plant organs or tissue (printing)

- blood.

Prepared mounts are left to air dry.

Furthermore, they need to be fixed:

- with fire

- with chemicals (more sensitive structure; methanol, acetone and formalin in case of pathogenic microorganisms).

This way, bacteria are literally fixed on the object glass and are not washed off during the washing procedure. 


\section{STAINING TECHNIQUES (METHODS)}

\section{Dyes for microbial staining}

Basic and acidic dyes are used for microbial staining. Bacterial cytoplasma is acidic and it can therefore be stained by basic anilin dyes. Other basic dyes are methylene blue, crystal violet, safranin, etc. Acidic dyes are eosin, fuchsine, erythrosin and Rose Bengal. Acidic dyes (eosin, fuchsine) are usually used in contrast staining of tissues. Dyes are usually found in crystal or powder form, which need to be dissolved in alcohol or water ( $1 \%$ solution).

Table 4: Most commonly used dyes for bacterial staining.

\begin{tabular}{|l|l|l|l|}
\hline blue dyes & red dyes & violet dyes & green dyes \\
\hline methylene & fuchsin & gentian violet & methylene green \\
\hline azure blue & \multirow{2}{*}{ saphranine } & crystal violet & malachite \\
\hline
\end{tabular}

\section{Staining methods}

Simple staining is reffered to as staining with only one dye. Microorganisms and tissues bear the same colour. In a differential staining procedure, several different dyes are used: at the same time (Giemsa staining) or successively (Gram staining). In that case, different kinds of microorganisms bear different colours.

Simple staining

- after Pfeiffer (1\% carbol fuxin solution)

- after Loeffler

- with methylene blue

\section{Differential staining}

- after Gram

- after Moeller and Schaffer-Fulton- method (bacterial spores)

- after Giemsa

- after Ziehl-Neelsen (acid-fast stain)

- after Hiss (bacterial capsule) 
Table 5: Selected staining techniques and their applications.

\begin{tabular}{|c|c|c|}
\hline TECHNIQUE: & PREPARATION OF MICROSCOPIC SLIDE: & APPLICATION: \\
\hline Wet mount & Drop of bacterial suspension & $\begin{array}{l}\text { Evaluation of morphology, } \\
\text { movement }\end{array}$ \\
\hline Colour staining & $\begin{array}{l}\text { Bacterial suspension, fixed on the } \\
\text { object glas }\end{array}$ & Different staining methods \\
\hline 1. Simple staining & One dye: e.g. methylene blue & Size and shape of microorganism \\
\hline 2. Differential staining & Two or more dyes & Differentition of microorganisms \\
\hline 2.1. Gram & Primary dye is followed by another dye & $\begin{array}{l}\text { Bacteria are divided into two groups: } \\
\text { 1. Gram-positive - blue violet; } 2 \text {. } \\
\text { Gram-negative - red }\end{array}$ \\
\hline 2.2. Ziehl-Neelsen & $\begin{array}{l}\text { Bacteria that are stained with carbol } \\
\text { fuchsine are decolourated (acid alcohol) } \\
\text { and further stained with methylene } \\
\text { blue }\end{array}$ & $\begin{array}{l}\text { Bacteria are differentiated after the } \\
\text { range of decolouration }\end{array}$ \\
\hline 2.3. Giemsa & Usually blood samples & $\begin{array}{l}\text { Differentiation between different } \\
\text { kind of blood cells }\end{array}$ \\
\hline 2.4. Schaeffer-Fulton & $\begin{array}{l}\text { Primary staining (=malachite green) is } \\
\text { followed by incubation and safranine } \\
\text { staining. }\end{array}$ & \multirow{2}{*}{ Endospores } \\
\hline 2.5. Moeller & $\begin{array}{l}\text { Primary staining (=carbol fuchsin) is } \\
\text { followed by incubation and methylene } \\
\text { blue staining. }\end{array}$ & \\
\hline 2.6. Hiss & $\begin{array}{l}\text { Staining with copper sulfate after } \\
\text { incubation with crystal violet dye }\end{array}$ & $\begin{array}{l}\text { Differentiation of capsule (light } \\
\text { violet) from bacteria (dark violet) }\end{array}$ \\
\hline Negative staining & Staining with ink (nigrosin) & $\begin{array}{l}\text { Microorganisms stay colourless, } \\
\text { background is dark }\end{array}$ \\
\hline
\end{tabular}




\section{Exercise 8: Microscopy and staining of bacterial specimens (mounts)}

\section{Material and instruments:}

- object / deck glasses

- set of dyes for Gram staining

- methylene blue dye for simple staining

- sterile plastic inoculation loop

- microscope

- distilled water

- probiotic yoghurt

- bacterial culture of Escherichia coli and Staphylococcus epidermidis

\section{Procedure:}

- Prepare two mounts:
A) $0.01 \mathrm{~mL}$ of diluted yoghurt suspension (simple staining with methylene blue dye)
B) Mixed bacterial culture (Gram staining)

A) Mounting procedure:

1. Spread a thin layer of the yoghurt suspension on the object glass.

2. Dry the mount in front of the opened fire.

3. Fix the mount with fire $(10 \times$ through the flame). Make sure to properly turn the object glass (the side with a mount should face up) .

\section{Simple staining (contrast):}

1. Pour methylene dye on the fixed mount and stain it for $5 \mathrm{~min}$.

2. Wash out the overdye on the slide with distilled water.

3. Air dry the mount.

4. Watch the mount under the microscope with the immersion oil and draw the microorganisms. 
Results of part A):

\section{Methylene blue}

Enlargement:

Shape of cells:

Colour of cells:

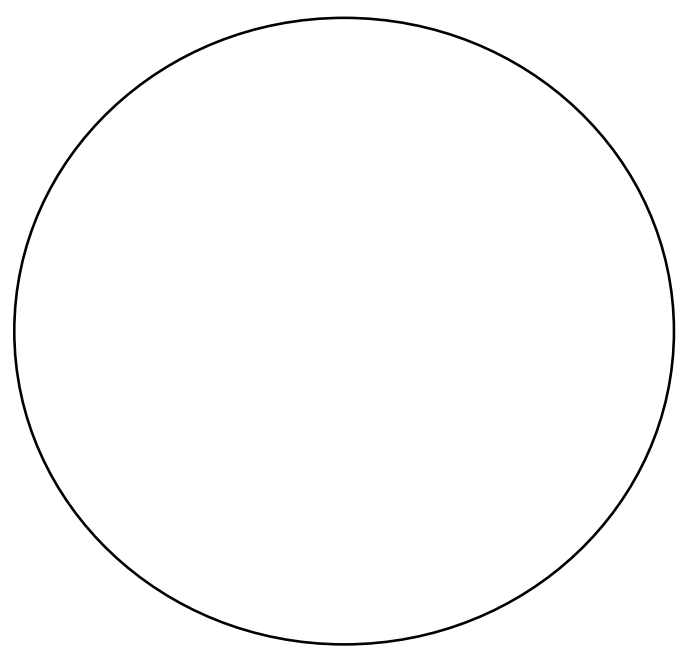

B) Mounting procedure:

1. Take a bit of bacterial material from the cultured agar plate and put it onto an object glass. Resuspend the material with a drop of saline solution directly onto the object glass and spread it in a thin layer all over the object glass.

2. Dry the prepared mount and fix it with the fire $(10 \times)$.

\section{Gram staining}

1. Put a few drops of a crystal violet dye onto the mount in order to cover it whole. Leave it staining for $1 \mathrm{~min}$.

2. Pour out the crystal violet dye.

3. Rinse the mount with lugol (iodine) solution, pour out and put it on the mount again. Leave it staining for $1 \mathrm{~min}$.

4. Pour out the lugol (iodine) solution with the help of distilled water for 5 sec.

5. Rinse the mount with $95 \%$ ethanol for $5-15$ sec or more (depending on the thickness of the applied material). Violet dye should be thoroughly washed away.

6. Rinse the ethanol with distilled water for $5 \mathrm{sec}$.

7. Put some drops of safranin dye on the mount. Leave it staining for $1 \mathrm{~min}$. 
8. Rinse the safranin dye carefully with distilled water.

9. Air dry the microscopic slide or wipe it carefully with a towel.

10. Observe the mount under the microscope and describe the stained microorganisms.

Results of part B):

Reference culture 1

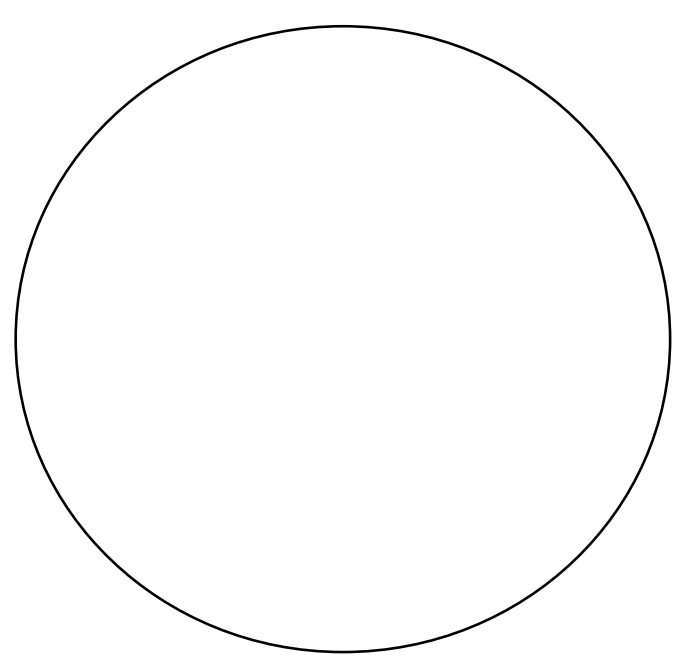

Gram + or -:
Reference culture 2

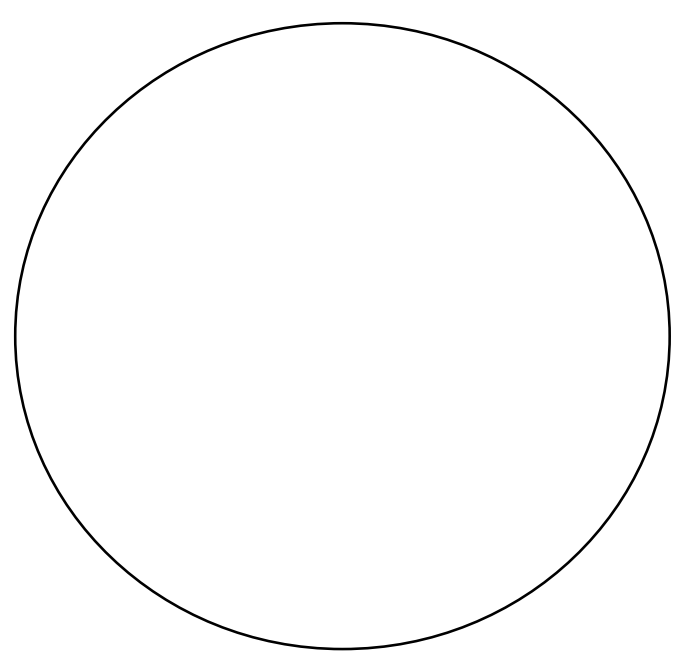

Gram + or -:

Shape:

Shape:

Throw the object glasses into the bins, provided at your working places! 


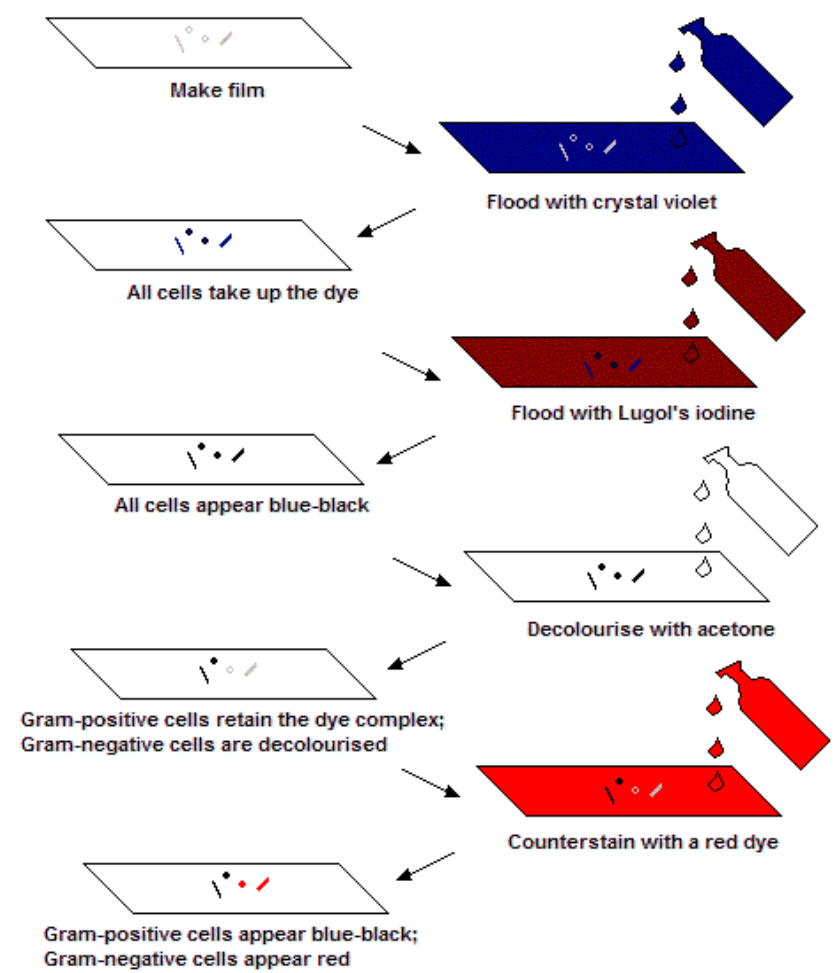

Figure 19: Gram staining sheme.

(Source: https://quizlet.com/25963991/micro-q3-b2-strep-staph-bacillus-flash-cards/).

Gram staining is the most important technique of differential staining applied for bacteria. Gram staining differs Gram positive bacteria from Gram negative. The technique was first described by Christian Gram in 1884. First, the cells are stained with crystal violet dye. Afterwards, lugol is added. Cells are discoloured with acetone or ethanol. Gram positive cells retain the colour (because of the thicker cell wall, a crystal violet - lugol (iodine) complex persists), Gram negative cells become colourless (ethanol washes the violet dye out of the cell wall) and need to be additionally stained with safranin or fuchsine.

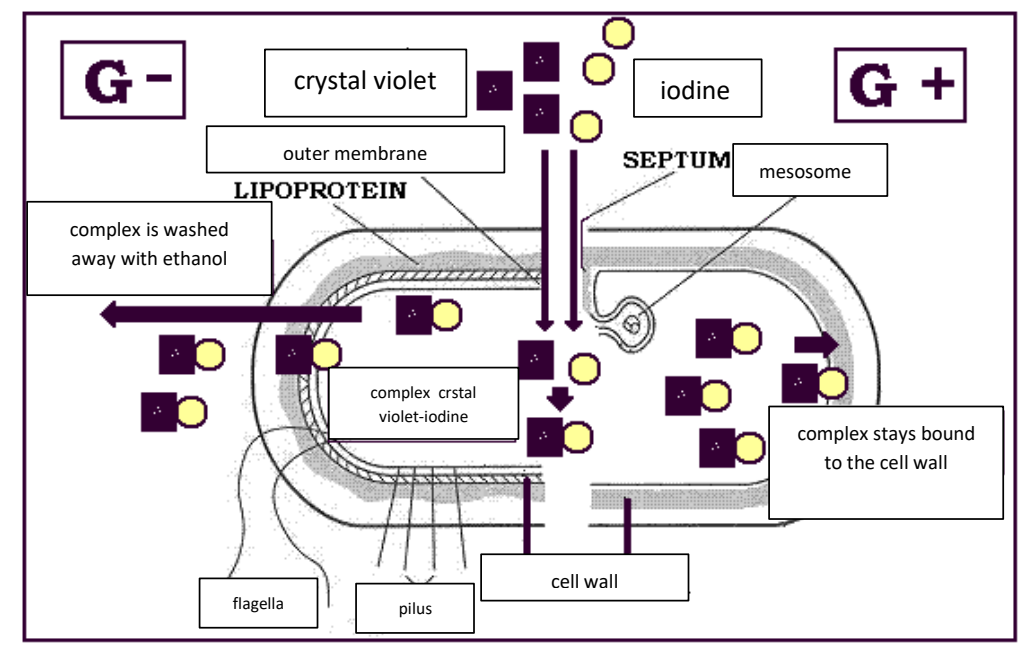

Figure 20: The mechanism of Gram staining.

(Source: Bratko Filipič, unpublished material) 


\section{MICROSCOPIC COUNT OF MICROORGANISMS}

Cells can be directly counted in a small amount of dryed or liquid sample. Disadvantages of so called direct counting methods are several: live cells do not differ from dead cells, low accuracy, problematic couting of microbes in concentrated samples (> $10^{6}$ cells $/ \mathrm{mL}$ ) that need prior dilution, low contrast.

\section{Exercise 9: Microorganism count}

\section{Material and instruments:}

- yoghurt

- object and deck glasses

- microscope

\section{Procedure:}

\section{a) Microorganism count in prepared mounts}

- Spread a known sample volumen (0.01 mL of yoghurt) on the object glass in a size of $1 \mathrm{~cm}^{2}$.

- Air dry the microscopic slide with the sample on it.

- Fix the mount with fire and stain it with methylene blue (leave the dye to work for at least 5 minutes), wash it with distilled water and air dry the slide.

- Count the cells in a few randomly chosen visible fields (5-20, depending of the concentration of bacteria in yoghurt).

Calculate the amount of cells in $1 \mathrm{~mL}$ of the sample, by using the average number of cells in one visible field with the formula bellow:

$$
\mathrm{N}=\mathrm{X} \times \mathrm{FM} \times 100
$$

where $\mathrm{N}$ means the number of cells $/ \mathrm{mL}, \mathrm{X}$ means a number of cells/visible field (average), 100 is a factor of the sample aliquot part and FM is a factor of the microscope. Factor of the microscope is: 


$$
\mathrm{FM}=\mathrm{P} / \pi \times \mathrm{r}^{2}
$$

where $P$ means a surface of the mount $\left(1 \mathrm{~cm}^{2}\right)$ and $r$ is the radius of the visible field (in optical microscope by $1000 \times$ magnification, $F M$ is in the range from 2000 to 2500$)$.

\section{Results a) part:}

Number of cells in yoghurt (cells / mL): 


\section{b) Cell count in a liquid sample using a counting chamber (Thoma, Neubauer) - haemocytometer}

A counting chamber is a specially designed object glass with a square net. The depth between the bottom of the chamber and the deck glass is $0.1 \mathrm{~mm}$. The net is devided into squares:

- surface of the large square is $1 / 25 \mathrm{~mm}^{2}$,

- surface of the small square is $1 / 400 \mathrm{~mm}^{2}$.

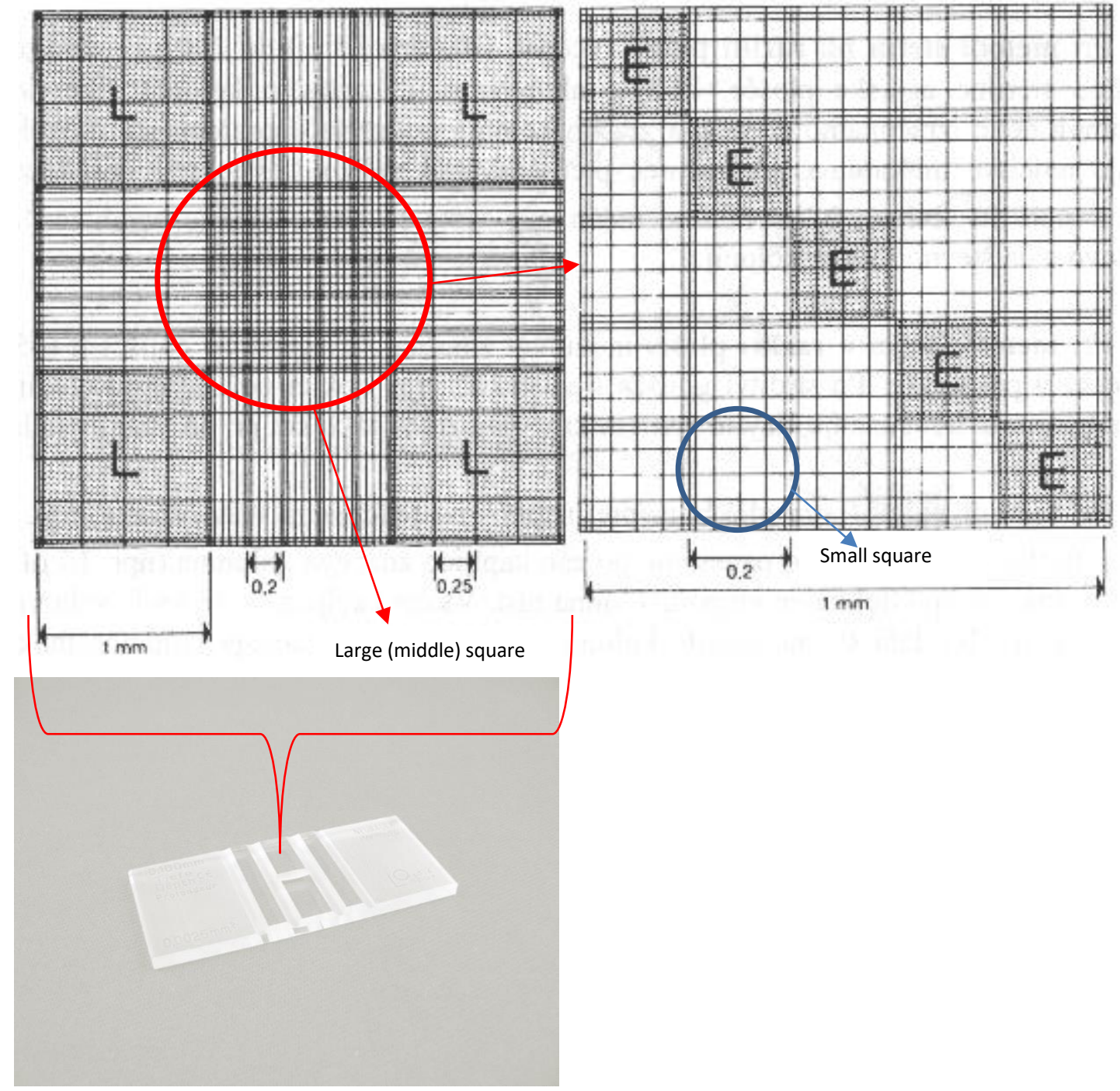

Figure 21: Haemocytometer (left) with the enlarged middle square (right). (Source: own).

- Put the deck glass on the counting chamber.

- Put a bit of a liquid sample between the chamber and the deck glass.

- Count the cells (different techniques). 
I. Calculate the number of cells in $1 \mathrm{~mL}$ of the sample with the help of the formula bellow:

$$
\mathrm{N}=\mathrm{X} \times 25 \times 10^{4}
$$

where $X$ is the average number of cells in one small square, 25 is the number of squares $/ \mathrm{mm}^{2}$ (large middle square), $10^{4}$ is a multiplying factor for a $1 \mathrm{~mL}$ volume.

\section{Result b) I. part:}

Concentration of cells in a suspension (cells $/ \mathrm{mL}$ ):

II. When the number of cells is low, counting of cells in larger squares can be performed. Count the cells in all four squares marked as 1 :

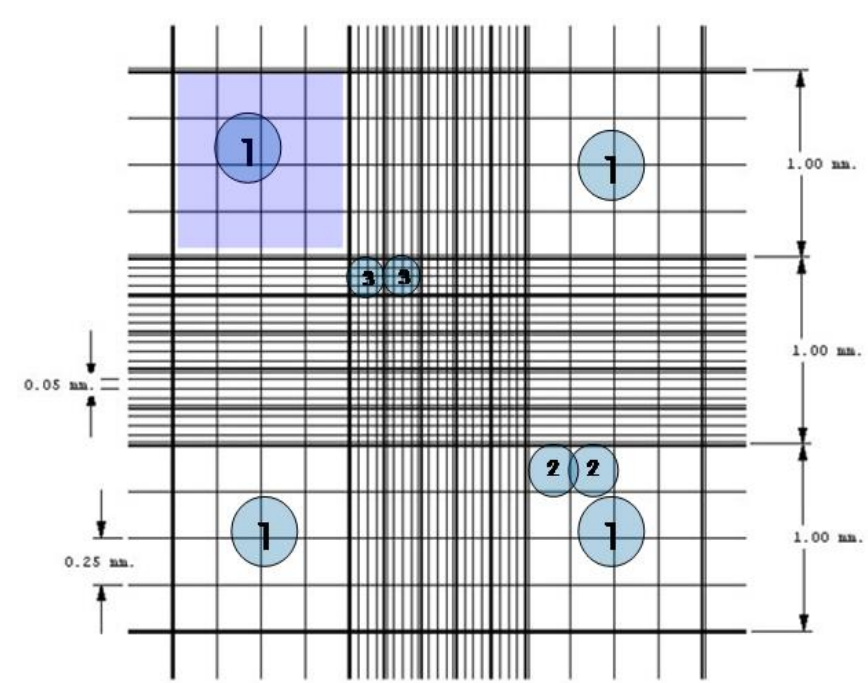

Figure 22: Haemocytometer.

(Source: $h$ ttp://www.celeromics.com).

Square 1: $\quad$ Area $=1 \mathrm{~mm} \times 1 \mathrm{~mm}=1 \mathrm{~mm}^{2}$

Volume $=1 \mathrm{~mm}^{2} \times 0.1 \mathrm{~mm}=0.1 \mathrm{~mm}^{3}=1 \times 10^{-4} \mathrm{~mL}$

Total Cells Counted $\times 10.000$

Concentration $=$

Number of squares 
Primec, M., Langerholc, T.: BASIC MICROBIOLOGY: Instructions on Laboratory Exercises

\section{Result b) II. part:}

Concentration of cells in a suspension (cells / $\mathrm{mL}$ ): 


\section{GROWTH OF MICROORGANISMS}

Growth on the cell level is defined as an increase in volume and mass of an individual cell. Growth of microorganisms on the population level is a result of a cell multiplication, a cell expansion and an increase in amount and mass of all cells. Energy source, nutrients and physical - chemical conditions are the main factors for a proper function and growth of every organism.

\section{Energy source}

Microorganisms can use energy from different sources, most commonly from oxidation of organic molecules. Some microorganisms have also the ability to obtain energy from the sun (solar energy) and by oxidation of inorganic molecules and elements such as $\mathrm{H}_{2}, \mathrm{H}_{2} \mathrm{~S}, \mathrm{NH}_{4}{ }^{+}, \mathrm{Fe}^{2+}, \mathrm{S}^{\circ}, \mathrm{S}_{2} \mathrm{O}_{3}, \mathrm{NO}_{2}{ }^{-}$.

Phototrophic microorganisms need solar energy.

Chemotrophic microorganisms obtain energy from oxidation of molecules (breathing or fermentation). Based on the nature of oxidized molecule, chemotrophic microorganisms can be further grouped as:

- litotrophic (oxidation of inorganic molecules, such as $\mathrm{H}_{2}, \mathrm{~S}, \mathrm{Fe}^{2+}, \mathrm{NH}_{4}^{+}$, $\mathrm{NO}_{2}^{-}$)

- chemoorganotrophic (oxidation of organic molecules).

Most of the bacteria are of chemoorganotrophic nature. As a source of energy, they use organic molecules, which are, in addition, a source of carbon and other chemical elements.

\section{Nutrients}

Besides energy, microorganisms need a source of carbon and other chemical elements. These elements are defined as nutrients:

- macro-nutrients (C, O, H, N, P, S, K, Mg, Na, Ca) - organisms need them in bigger amounts,

- micro-nutrients (Fe, Co, Cr, Mn, Mo, Ni, Se, W, V, Zn), - organisms need them in small amounts, i.e. traces. 
Specifically, according to the carbon source, microorganisms are classified as:

- autotrophic - organisms that use $\mathrm{CO}_{2}$ as carbon source (cyanobacteria)

- heterotrophic - organisms that use carbon exclusively from organic molecules.

Table 6: Most frequent elements used for the growth of microorganisms.

\begin{tabular}{|c|c|}
\hline Element & Source in growth medium \\
\hline Carbon & $\mathrm{CO}_{2}, \mathrm{HCO}_{3}^{-}$, sugars, protein extracts \\
\hline Hydrogen & water, organic material, $\mathrm{H}_{2}$ \\
\hline Oxygen & water, $\mathrm{O}_{2}$ \\
\hline Nitrogen & $\begin{array}{l}\text { aminoacids, nitrogen basis, } \mathrm{NH}_{4} \mathrm{Cl},\left(\mathrm{NH}_{4}\right)_{2} \mathrm{SO}_{4}, \mathrm{KNO}_{3} \text {, } \\
\mathrm{N}_{2}\end{array}$ \\
\hline Phosphorus & $\mathrm{Na}_{2} \mathrm{HPO}_{4}, \mathrm{KH}_{2} \mathrm{PO}_{4}$ \\
\hline Sulphur & $\mathrm{Na}_{2} \mathrm{SO}_{4}, \mathrm{H}_{2} \mathrm{~S}$, organic material \\
\hline Potassium & $\mathrm{KCl}, \mathrm{K}_{2} \mathrm{HPO}_{4}$ \\
\hline Magnesium & $\mathrm{MgCl}_{2}, \mathrm{MgSO}_{4}$ \\
\hline Calcium & $\mathrm{CaCl}_{2}, \mathrm{CaCO}_{3}$ \\
\hline Sodium & $\mathrm{NaCl}$ \\
\hline Iron & $\mathrm{FeCl}_{3}, \mathrm{Fe}\left(\mathrm{NH}_{4}\right)\left(\mathrm{SO}_{4}\right)_{2}$ \\
\hline Trace elements & $\begin{array}{l}\mathrm{CoCl}_{2}, \mathrm{ZnCl} 2, \mathrm{Na}_{2} \mathrm{MoO}_{4}, \mathrm{CuCl}_{2}, \mathrm{MnSO}_{4}, \mathrm{NiCl}_{2}, \\
\mathrm{Na}_{2} \mathrm{SeO}_{4}, \mathrm{Na}_{2} \mathrm{WO}_{4}, \mathrm{Na}_{2} \mathrm{VO}_{4}\end{array}$ \\
\hline Growth factors & vitamins, aminoacids, purines, pyrimidines \\
\hline
\end{tabular}

\section{Physical - chemical factors}

Microbiological growth media have characteristic physical and chemical parameters (activity of hydrogen ions - $\mathrm{pH}$, water activity, osmotic pressure, viscosity). Environmental factors, such as temperature, oxygen, light, pressure and magnetic field, also play an important role in microorganism growth.

\section{Concentration of hydrogen ions $(\mathrm{pH})$}

Most bacteria grow in a relatively narrow $\mathrm{pH}$ range (between 6.5 and 7.5). Some of them prefer living in extreme conditions - acidophilic bacteria grow at $\mathrm{pH}$ 14 , alkaliphiles like the $\mathrm{pH}$ range from 9 to 10 . Unlike bacteria, yeasts and moulds 
tolerate a wider $\mathrm{pH}$ range (from $\mathrm{pH} 5$ till 9). During their growth, microorganisms excrete different organic acids, which reduce the $\mathrm{pH}$ in the medium and consequently inhibit their own growth. Some of the medium ingredients have a weak buffering activity. However, in most of the media strong buffering components are added (phosphates, carbonates).

\section{Temperature}

Each microorganism has its own optimal, minimal and maximal growth temperature.

- Temperature optimum: is a temperature, where microorganism grows the fastest.

- Temperature maximum: is the highest temperature, where the growth is still observed.

- Temperature minimum: is the lowest temperature, where the growth is still observed.

Temperature optimum, minimum and maximum refer to the growth of microorganism, not to its survival. According to the growth temperature, microorganisms are described as:

Table 7: Division of microorganisms according to the growth temperature.

\begin{tabular}{|c|c|c|c|}
\hline \multicolumn{4}{|c|}{ Growth temperature $\left({ }^{\circ} \mathrm{C}\right)$} \\
\hline $\begin{array}{c}\text { psihrophilic } \\
\text { (cryophilic) }\end{array}$ & minimum & optimum & maximum \\
\hline mezophilic & $-5-0$ & $5-15$ & $15-20$ \\
\hline termophilic & $10-20$ & $20-40$ & $40-45$ \\
\hline extreme termophilic & $25-45$ & $45-60$ & $60-80$ \\
\hline
\end{tabular}

Most of the well known bacteria grow between $28^{\circ} \mathrm{C}$ and $38^{\circ} \mathrm{C}$. These are so called mesophilic bacteria (haemothermophilic- $37^{\circ} \mathrm{C}$ ). Psihrophilic bacteria grow at $16^{\circ} \mathrm{C}$ (or lower). Thermophilic bacteria grow faster at $60^{\circ} \mathrm{C}$. Temperatures above $37^{\circ} \mathrm{C}$ (e.g. $42^{\circ} \mathrm{C}$ ) or lower (e.g. $24^{\circ} \mathrm{C}$ ) are used to differentiate species or as a selective factor during the isolation procedure.

\section{Oxygen and other gases}


Microorganisms can be grouped according to their growth in the presence of oxygen:

Strict or obligate aerobic microorganisms grow only in oxygen presence. Their metabolism is exclusively respiratory.

Most of the known bacteria belong to the group of facultative anaerobic microoganisms. They can grow in an atmosphere with or without oxygen. A presence of oxygen determines whether they use a respiratory or fermentative type of metabolism. Respiratory metabolism is energetically more efficient (e.g. Enterobacteriaceae family).

Microaerophilic microorganisms (e.g. Campylobacter and Actinomyces) need reduced partial oxygen pressure (5 - 10\%) and increased partial carbon dioxide pressure.

Strict or obligate anaerobes grow in an atmosphere without oxygen. Their metabolism is exclusively fermentative. One of the most important strict anaerobe is genus Clostridium, methanogene and sulphate reductive bacteria and most of the bacteria from Bacteroides genus. Aerotolerant anaerobes are strictly fermentative microorganisms (e.g. lactic acid bacteria). They cannot use oxygen, although it is not toxic to them. They grow better in anaerobic conditions.

Knowledge about microorganism's oxygen demands is important, when it comes to their culturing and taxonomy. One of the easiest way to evaluate these conditions is by culturing the bacteria in a so called agar deep. Agar deep is a hard or half hard medium in a tube. Before inoculation, agar deep needs to be heated to $100^{\circ} \mathrm{C}$ to convert into a liquid phase. In this way, a reduction of oxygen is obtained. By cooling down, an oxygen gradient is established. After inoculation and incubation, bacteria grow down the whole tube, according to their oxygen tolerance.
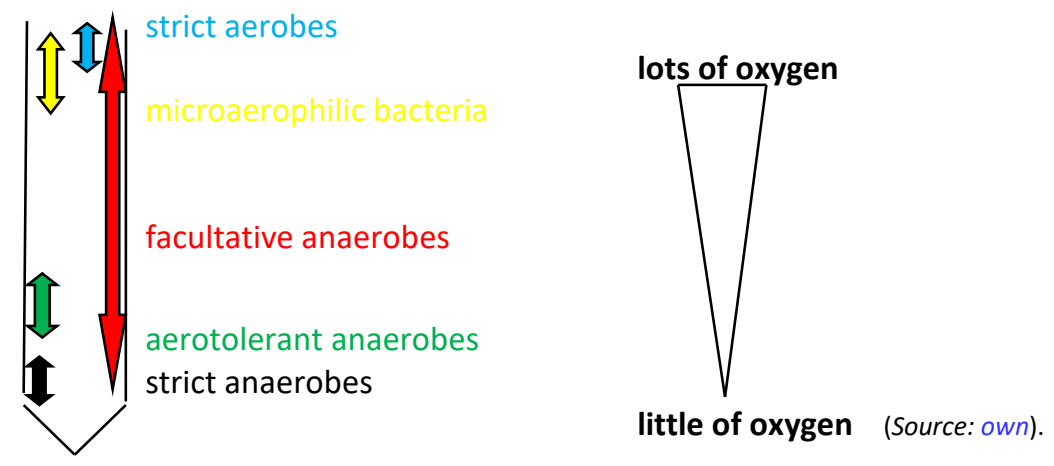

Figure 23: Growth of different bacteria in agar deep. 


\section{Water activity}

Water is absolutely neccessary for the growth of microorganisms. It serves as a source of oxygen and hydrogen and as a barrier to temperature changes. The amount of water available to bacteria is reffered to as water activity (aw). Water activity depends on the concentration on other solutes in the media, which bind to water and hence reduce its activity and availability to microbes. Most bacteria have their optimal water activity above 0.99 . Halophilic microorganisms grow in an increased concentration of $\mathrm{NaCl}$, which consequently reduces water activity. 
Exercise 10: Effect of environmental factors on the growth of microorganisms Temperature

\section{Material and instruments:}

- pure culture:

- nutrient agar

- inoculation loop

\section{Procedure:}

- Take a small amount of bacteria and proceed with the streaking technique on 4 nutrient agars (one bacterial strain / 4 agars)

- Incubate each agar at a different temperature: $4^{\circ} \mathrm{C}, 21^{\circ} \mathrm{C}, 37^{\circ} \mathrm{C}$ and $45^{\circ} \mathrm{C}$.

- After the incubation, evaluate the effect of the temperature on the microorganism's growth (extent of colony growth, size of colonies,...).

\section{Results:}

Effect of temperature on the growth of

\begin{tabular}{|l|c|c|c|c|}
\hline Micoorganism & $4^{\circ} \mathrm{C}$ & $21^{\circ} \mathrm{C}$ & $37^{\circ} \mathrm{C}$ & $45^{\circ} \mathrm{C}$ \\
\hline & & & & \\
\hline & & & & \\
\hline & & & & \\
\hline
\end{tabular}




\section{Growth media}

Substrates that facilitate the growth of microorganisms are known as growth media. Each growth medium should be sterile, transparent and of optimal pH. Prepared media are usually kept in a fridge till their use. Some bacteria need freshly prepared growth media.

Growth media are, according to their composition, divided into:

- Natural: consist of nutrients coming from animal or plant origin, but chemically non-defined (beef extract, yeast extract, peptone, milk, serum)

- Composed (peptone, meat extract, yeast extract)

- Synthetic: consist of exclusively chemically defined nutrients in known concentrations

Growth media are, according to their purpose, divided into:

- Basic, nutrient (nutrient agar, nutrient broth, peptone) They are the simpliest media and therefore satisfy the growth of many bacteria.

- Enriched (addition of blood, plant juice)

- Special:

They are basic media with the addition of different substances:

selective: consists of supplements that select the growth of only specific types of bacteria (bile, $\mathrm{NaCl}$ in higher concentrations of $5-15 \%$, potassium thelurite, antibiotics, chemoterapeutics),

differential: different kinds of bacteria grow differently, depending on their metabolism of nutrients in the medium.

Growth media are, according to agar content, divided into:

- Liquid (no agar)

- Half solid (0.5\% of agar)

- Solid (1.5 - $2 \%$ of agar)

Agar-agar is a polysaccharide (galactose, galacturonic acid) derived from certain species of algae. Agar microbiological plates consist of $1.5 \%$ of agar. Broths (boujons) have the same composition as solid media, except for agar. They are used mostly for increasing the amount of bacteria needed or for selective enrichment of different bacteria. Solid media are prepared for agar plates, for inoculation tests, for bacteria storage, for oxygen dependant tests and for some biochemical tests in tubes. Half solid media consist of smaller amounts of agar. At a higher temperature, they turn into their liquid phase. Half solid media are used in the overlaying technique. 
Weighing, preparation, sterilisation and pouring technique of synthetic media

General rules to ensure a good quality of medium preparation in a laboratory

\section{A) Weighing}

The original package of media bears information about media preparation. The whole weighing procedure is performed following the manufacturer's instructions (g of medium / $\mathrm{mL}$ of distilled water). Grammature has to be at a 0.1 g accuracy.

\section{B) Reconstitution}

Synthetic agar is reconstituted with distilled water. Components of liquid media are usually soluble at room temperature and change into a clear solution. Most of the synthetic media need to be autoclaved immediately upon preparation.

\section{C) Activity of hydrogen ions - $\mathrm{pH}$}

$\mathrm{pH}$ is very important for bacterial growth, therefore a thorough check up of $\mathrm{pH}$ after reconstitution / sterilization is mandatory.

\section{D) Pour plating technique}

Pouring of agar into a Petri dish plate occurs at around $45^{\circ} \mathrm{C}$ to $55^{\circ} \mathrm{C}$ to avoid condensation. After the agar has solidified, the agar plates can be kept in a fridge for a few weeks. It is important to properly wrap them before storage as water evaporation may occur over time.

Liquid media (broth) are filled into glass tubes before sterilisation. After sterilisation, tubes may be kept in a fridge for a few weeks.

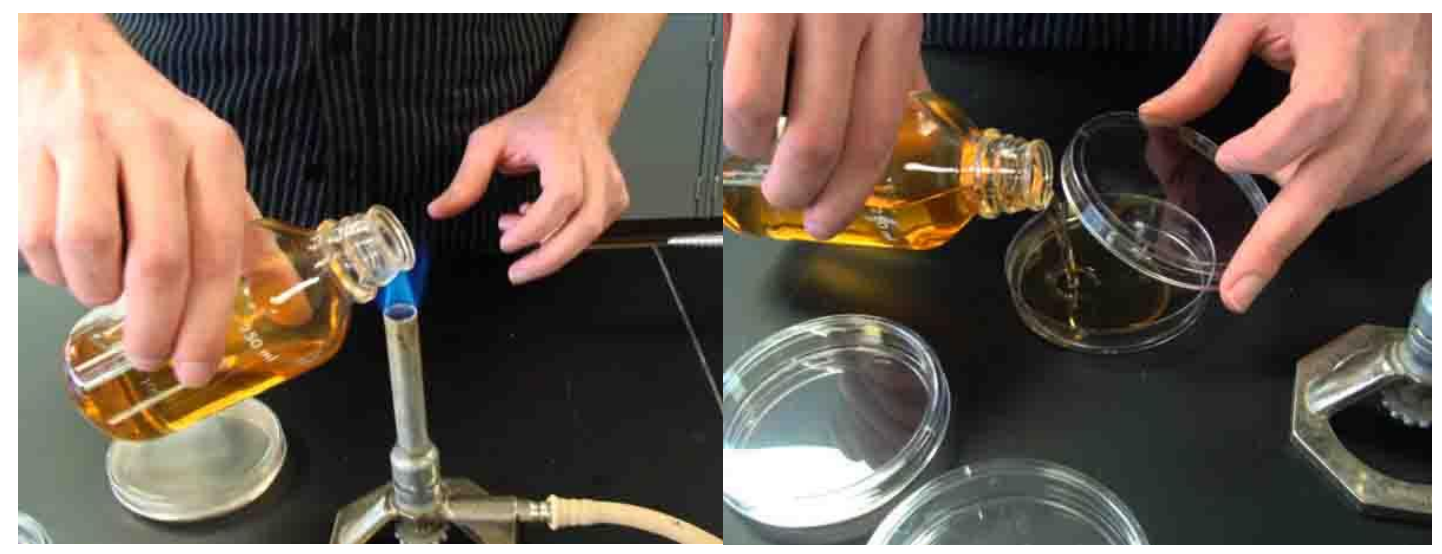

Figure 24: Pour plating technique. (Source: own).

\section{E) Preparation of supplements}

Supplements (inhibitors, growth factors) are prepared and added following the manufacturer's instructions. They are usually sensitive to high temperature and 
therefore need to be added to the medium aseptically after autoclaving / cooking.

\section{F) Agar reconstitution}

Some media can be prepared in advance in Erlenmayer bottles. Just before their use, media are reconstituted in their liquid state (sulphite agar, plate count agar) by heating. If additional supplements are needed, high temperature should be taken into account. 


\section{Exercise 12: Growth of microorganisms on agar plates}

The growth of a heterogeneous culture may be selective or differential, based on the bacterial physiological specifics or different metabolisms, respectively.

\section{Material and instruments:}

- agar plates (nutrient, MRS, ECC)

- soil suspension $\left(10^{-1}\right)$

- water from a river

- skin

\section{Procedure:}

- Divide the bottom of each agar plate into three equal parts.

- Apply each material with the help of the inoculation loop onto a proper part of the agar plate.

- Incubate agar plates at $37^{\circ} \mathrm{C}$ for $1-2$ days.

\section{Results:}

- After the incubation period, check the growth of microorganisms on each part of the different agar plates.

Do the same microorganisms appear on all agar plates? Explain! 


\section{Nutrient agar}

\begin{tabular}{|c|c|c|c|}
\hline $\begin{array}{c}\text { Growth } \\
(\mathrm{Y} / \mathrm{N})\end{array}$ & soil & river & skin \\
\hline $\begin{array}{c}\text { Colour of } \\
\text { colonies }\end{array}$ & & & \\
\hline $\begin{array}{c}\text { Shape of } \\
\text { colonies }\end{array}$ & & & \\
\hline
\end{tabular}

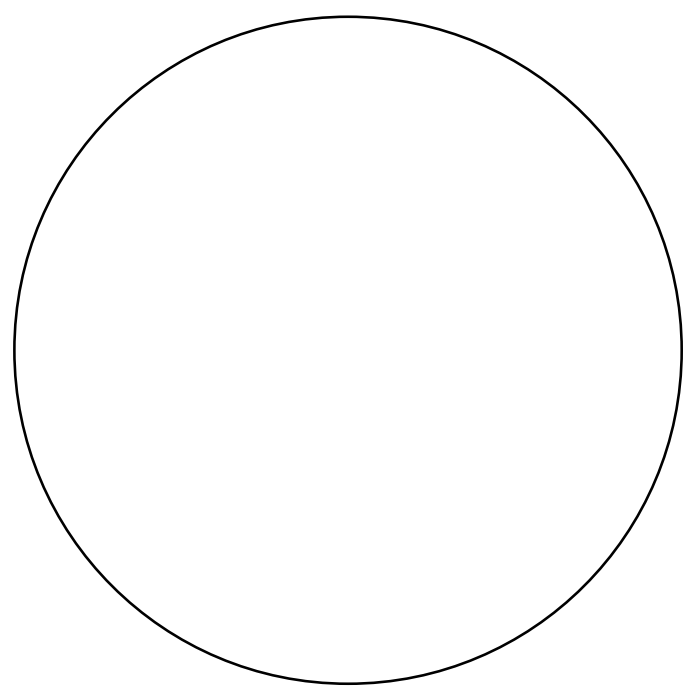

\section{ECC agar}

\begin{tabular}{|c|c|c|c|}
\hline $\begin{array}{c}\text { Growth } \\
(\mathrm{Y} / \mathrm{N})\end{array}$ & soil & river & skin \\
\hline $\begin{array}{c}\text { Colour of } \\
\text { colonies }\end{array}$ & & & \\
\hline $\begin{array}{c}\text { Shape of } \\
\text { colonies }\end{array}$ & & & \\
\hline
\end{tabular}

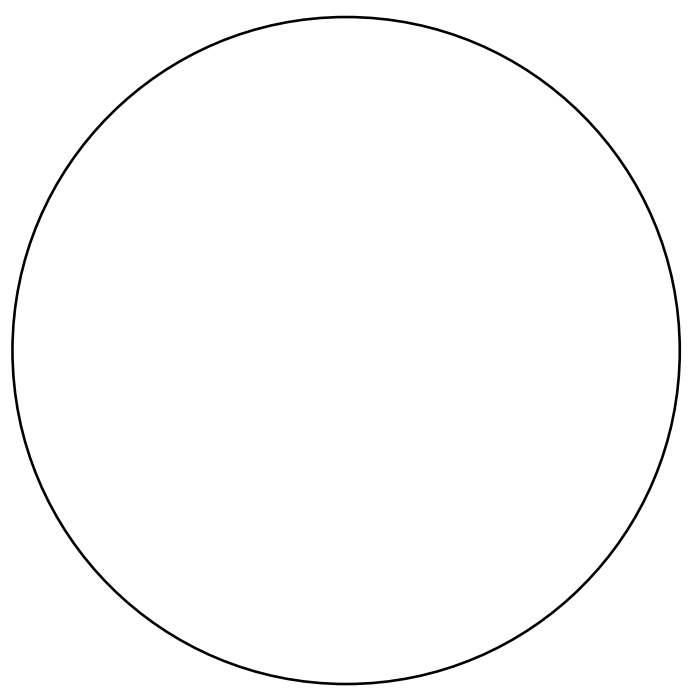

\section{MRS agar}

\begin{tabular}{|c|c|c|c|}
\hline $\begin{array}{c}\text { Growth } \\
(\mathrm{Y} / \mathrm{N})\end{array}$ & soil & river & skin \\
\hline $\begin{array}{c}\text { Colour of } \\
\text { colonies }\end{array}$ & & & \\
\hline $\begin{array}{c}\text { Shape of } \\
\text { colonies }\end{array}$ & & & \\
\hline
\end{tabular}

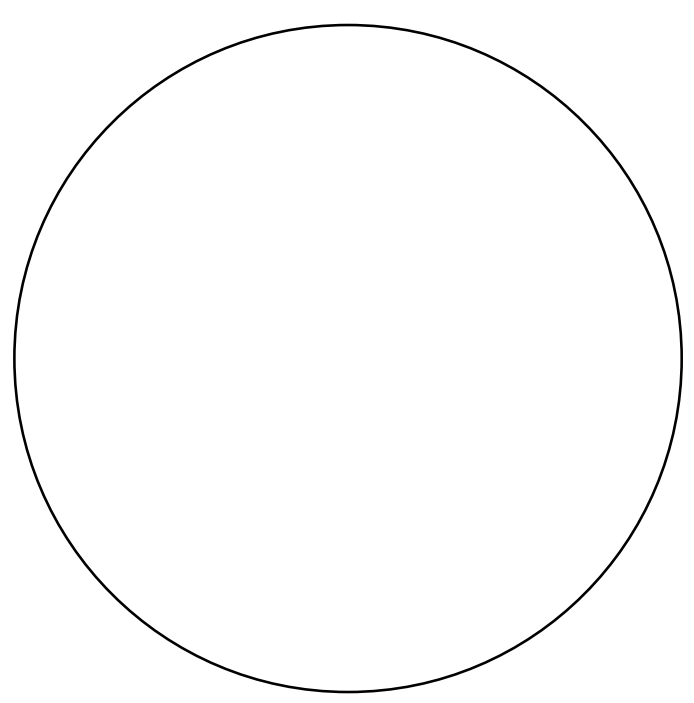




\section{PREPARATION OF FOOD AND FEED SAMPLES FOR MICROBIOLOGICAL ANALYSIS - SAMPLING}

The preparation of samples for microbiological analysis requires aseptic conditions to prevent a contamination from the environment and to prevent the spreading of potentially pathogenic sample. Samples need to be homogenized prior to starting their analysis.

\section{Sampling instructions}

Homogenisation procedure

1. Weigh the sample in an appropriate stomacher bag and dilute it with a saline solution or peptone.

2. Put the bags into the stomacher and properly close the door.

3. Homogenise for 3 minutes and proceed with the sample preparation.

Preparation of different food for microbiological analysis

Meat, meat products, chopped meat and intestines:

Mix $20 \mathrm{~g}$ of sample with the help of a sterile spoon, scalpel or scissors. Add 1:9 saline solution or peptone $(180 \mathrm{~mL})$ and homogenise.

\section{Cheese and fermentated products (yoghurt, kefir):}

Hard cheese: Remove a 0.5 - $1 \mathrm{~cm}$ thick layer aseptically and take $20 \mathrm{~g}$ of sample from deeper parts of the cheese. Soft cheese needs to be mixed before weighing. Add $180 \mathrm{~mL}$ of $2 \% \mathrm{Na}$-citrate solution $\left(45^{\circ} \mathrm{C}\right)$ and homogenise.

After opening yoghurts and other milk products, the packaging should be disinfected.

\section{'Ready to eat' food (pleskavica, čevapčiči, steaks):}

Aseptically cut the packaging with scissors, weigh off $20 \mathrm{~g}$ of the sample, add 180 $\mathrm{mL}$ of saline solution or peptone and homogenise. 


\section{Spices, herbs:}

Mix small bags and aseptically open them with scissors.

\section{Vegetable juice, vegetable sauce and ketchup:}

Pipette $20 \mathrm{~g}$ of sample and add $180 \mathrm{~mL}$ of saline solution or peptone. Homogenise in the stomacher.

\section{Decimal dilutions}

- Basic dilution: is the sample suspension obtained after diluting the sample with a 9-times bigger quantity of saline solution or peptone (1:9).

- Dilutions after: is the suspension obtained after diluting the basic solution. For further dilutions, saline solution or peptone are frequently used. 
Exercise 14: Sample dilution preparation and evaluation of the microorganism concentration

\section{Material and instruments:}

- peptone $(9 \mathrm{~mL}$ in sterile test tubes $(15 \mathrm{~mL}))$

- pipettes

- empty sterile Petri dishes

- tap water (dilutions $10^{-1}$ to $\left.10^{-2}\right)\left(10^{-3}\right.$ and $10^{-4}$ )

- water from the river (dilutions $10^{-1}$ to $\left.10^{-5}\right)\left(10^{-6}\right.$ and $\left.10^{-7}\right)$

- soil (dilutions $10^{-1}$ to $\left.10^{-6}\right)\left(10^{-7}\right.$ and $\left.10^{-8}\right)$

1. Homogenise each sample by diluting it with $90 \mathrm{~mL}$ of peptone broth (dilution of $10^{-1}$ ), mix thoroughly at least for $5 \mathrm{~min}$.

2. Take out $1 \mathrm{~mL}$ of the $10^{-1}$ dilution and put it into the first test tube $\left(10^{-}\right.$ $\left.{ }^{2}\right)$ with $9 \mathrm{~mL}$ of peptone.

3. Change the tip of the pipette and proceed with the dilution: vortex the first test tube and again take out $1 \mathrm{~mL}$ of the solution and put it into the second test tube $\left(10^{-3}\right)$.

4. Repeat the dilution procedure until the desired dilution.

5. Prepare empty sterile Petri dishes. For each dilution, you will need two Petri dishes (parallels). Label the Petri dishes with the number of the group, name of the sample and a proper dilution.

6. When finished with diluting, take out $1 \mathrm{~mL}$ of the individual dilutions and put them in the empty Petri dishes (for each dilution prepare two Petri dishes - parallels). Always vortex the test tube before taking out the $1 \mathrm{~mL}$.

7. Pour (never directly on the sample solution!) the prepared and cooled down $\left(43-47^{\circ} \mathrm{C}\right)$ liquid plate count agar into Petri dishes, mix it thoroughly and leave it to solidify.

8. Incubate the plate count agar at $30^{\circ} \mathrm{C}$ for $72 \mathrm{~h}$.

9. After incubation, count the colonies. 


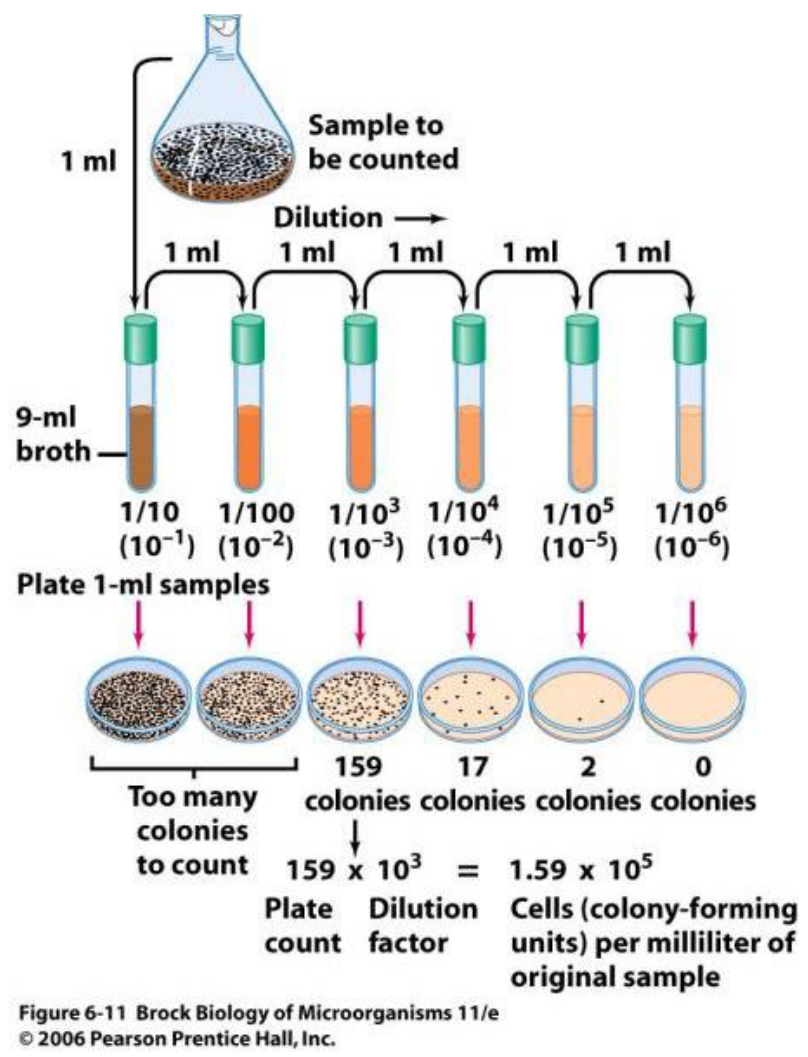

Figure 25: Sample dilution preparation and pouring technique.

\section{Evaluation of the total microorganism count (Colony Forming Units (CFU)/g or $\mathrm{mL}$ of a sample)}

Colony count after 3 days (incubation at $30^{\circ} \mathrm{C}$ )

With this method, aerobic heterotrophic microorganisms are evaluated.

\section{Procedure:}

- After the incubation, count the grown colonies.

- For quantification, use only the first possible agar plates, where you can reliably count colonies (plates with 30-300 typical colonies are used). However, it may be different for other agars.

- Use the formula bellow to calculate the number of $\mathrm{CFU} / \mathrm{mL}$ of your sample, by taking into account the dilutions, the volume of inoculum and the number of Petri dishes you used for counting:

$$
\mathrm{N}(\mathrm{CFU} / \mathrm{mL})=\frac{\Sigma C}{V \times \mathrm{n} \times d}
$$


$\sum C$ - number of all counted colonies on all agar plates,

$\mathrm{V}$ - volume of inoculum in each plate (in $\mathrm{mL}$ ),

$\mathrm{n}$ - number of Petri dishes used for counting,

$\mathrm{d}$ - factor of dilution $\left(10^{\mathrm{x}}\right)$, where the $\mathrm{X}$ means the first selected dilution, where the total count has been performed.

Write the result as the number $\mathrm{x}$ of microorganisms per millilitre (liquid products) or per gram (other products), which is colony forming units in $1 \mathrm{~mL}$ (CFU / mL) or $1 \mathrm{~g}$ (CFU / g) of each sample. 


\section{FUNGI}

Fungi have a eucariontic cell structure and they can be recognized by their macro-/micromorphological characteristics such as shape. According to their macromorphological characteristics, two types can be determined:

First type are yeasts: transparent, mucous colonies.

Second type are moulds: phylamentous micellium.

Different incubation temperatures can affect the morphology of some yeasts and moulds. This is called dimorphism.

Their identification on agar:

- colony characteristics (morphology, structure)

- staining of colonies

- speed of growth and pigmentation of mycelium, that grows into the agar

- spore characteristic structures

\section{Cultivation on agar plate}

Cultivation of yeasts (Saccharomyces cerevisiae) on solid agar is the most common and practical way of evaluating their morphology, growth and biochemical characteristics.

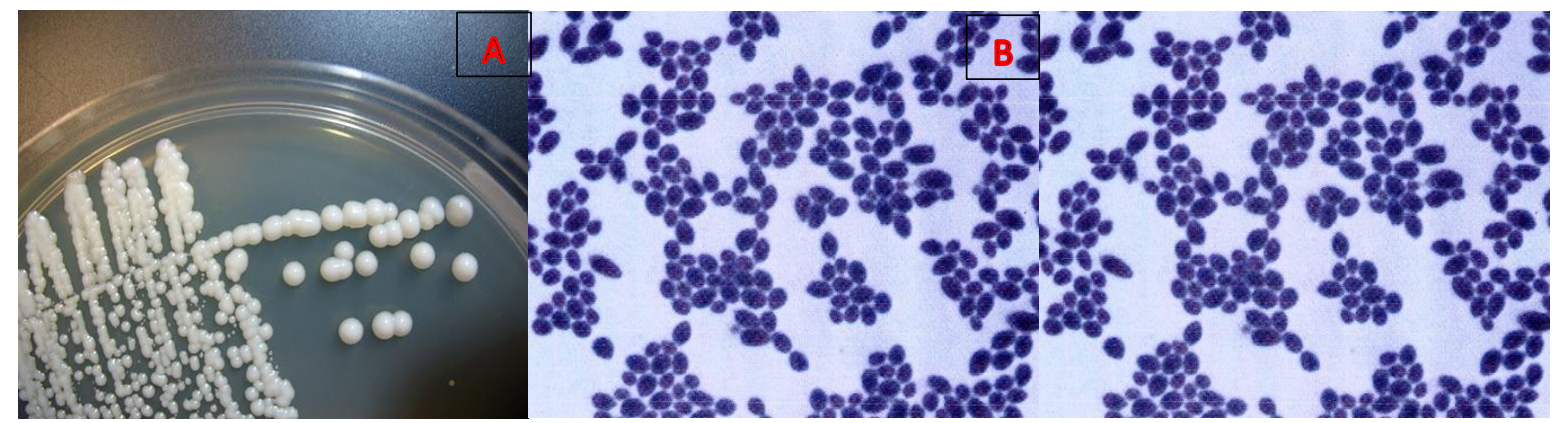

Figure 26: Yeasts (Saccharomyces cerevisiae).

(A) Colonies on agar plate, (B) Microscopic slide preparation. Yeast cells are stained by Gram (Source: own). 
Exercise 15: Sample preparation, sample inoculation and count of microorganisms

Material and instruments:

- animal feed, wine or fruit juice

- potato dextrose agar

- peptone water

- sterile tubes for dilutions

- pipettes

\section{Procedure:}

- Add $90 \mathrm{~mL}$ of saline solution or peptone to $10 \mathrm{~g}$ of sample $\left(10^{-1}\right)$.

- Mix well and proceed with dilutions 1:9 in tubes: $10^{-2}, 10^{-3},\left(10^{-4}\right)$.

- From $10^{-1}, 10^{-2}, 10^{-3}$ in $\left(10^{-4}\right)$ dilutions, take $100 \mu \mathrm{L}$ out and spread the whole volume on the agar plates (Do not forget the parallels!).

- Incubate agar plates at room temperature with different incubation times:

- After the incubation at different times, count all the colonies (moulds and yeasts) and calculate the CFU/g sample (see the formula before).

- At each stage of an incubation time, take a small amount of a colony with an inoculation loop and perform a prepared mount with simple staining.

- Describe the morphological features.

- Write the results in the table bellow.

Results (CFU/mL sample):

\begin{tabular}{|c|c|c|}
\hline culture & yeast & moulds \\
\hline incubation time & & \\
\hline
\end{tabular}

Morphological characteristics of the culture:

\begin{tabular}{|c|c|c|}
\hline culture & yeast & moulds \\
\hline incubation time & & \\
\hline
\end{tabular}




\section{REFERENCES}

\section{Cited references}

[1] Bell, C. et al., 2005. Food microbiology and Laboratory Practice. $1^{\text {st }}$ Edition. Oxford: Blackwell science.

[2] Bole, H.V., 1996. Osnove dela v mikrobiološkem laboratoriju. Priročnik za vaje iz mikrobiologije za veterinarje. 1. Izd. Ljubljana: Veterinarska fakulteta.

[3] Demain, A.L. (ur.), Davies, J.E., 1999. Manual of industrial microbiology and Biotechnology. $2^{\text {nd }}$ Edition. Washington DC, USA: American Society for Microbiology.

[4] Dragaš, A.Z., Filipič, B., Gubina, M. et al., 1988. Praktikum [iz mikrobiologije]: za študente medicine. Ljubljana: Medicinska fakulteta, Katedra za mikrobiologijo in imunologijo, (Ljubljana: J. Pleško).

[5] Filipič, B., Cenčič, A., 1999. Splošna mikrobiologija. Navodila za vaje. 1. Izd. Maribor: Fakulteta za kmetijstvo.

[6] Filipič, B., 2011. Unpublished material.

[7] Jeršek, B., 2009. Higiena živil [elektronski vir]: Laboratorijske vaje za študente živilstva in prehrane. 2. dopolnjena izd. Ljubljana: Biotehniška fakulteta, Oddelek za živilstvo.

[8] Madigan, M.T., Martinko, J.M., 2006. Brock Biology of Microorganisms. $11^{\text {th }}$ Edition. Pearson Prentice Hall, Inc.

[9] Nahberger Marčič, V., 2009. Živilska mikrobiologija in biotehnologija. Vaje iz mikrobiologije. 1. Izd. Maribor: Izobraževalni center Piramida, Višja strokovna šola, 2009 (Maribor: GBT Marksl). 
[10] Pollack, R., Findlay, L., Mondschein, W., Modesto, R.R., 2009. Laboratory exercises in microbiology. $3^{\text {rd }}$ Edition. John Wiley and Sons.

[11] Rupnik, M., Zalar, P., Turk, M., Janc, M., 2005. Splošna mikrobiologija: navodila za vaje, (Knjižna zbirka Scripta). 3. dopolnjena izd. Ljubljana: Študentska založba.

[12] Talaro, A., Talaro, K.P., 1999. Foundations in microbiology. $3^{\text {rd }}$ Edition. The MacGraw-Hill Companies, Inc.

[13] ISO 6887-1:1999(en). Microbiology of food and animal feeding stuffs Preparation of test samples, initial suspension and decimal dilutions for microbiological examination - Part 1: General rules for the preparation of the initial suspension and decimal dilutions. [https://www.iso.org/obp/ui/\#iso:std:iso:6887:-1:ed-1:v1:en].

[14] ISO 6887-2:2003(en). Microbiology of food and animal feeding stuffs Preparation of test samples, initial suspension and decimal dilutions for microbiological examination - Part 2: Specific rules for the preparation of meat and meat products. [https://www.iso.org/obp/ui/\#iso:std:iso:6887:-2:ed-1:v1:en].

[15] ISO 6887-5:2010 (en). Microbiology of food and animal feeding stuffs -Preparation of test samples, initial suspension and decimal dilutions for microbiological examination -- Part 5: Specific rules for the preparation of milk and milk products. [https://www.iso.org/obp/ui/\#iso:std:iso:6887:-5:ed-1:v1:en].

[16] ISO 7218:2007(en). Microbiology of food and animal feeding stuffs General requirements and guidance for microbiological examinations. [https://www.iso.org/obp/ui/\#iso:std:iso:7218:ed-3:v1:en].

[17] ISO 4833-1:2013(en). Microbiology of the food chain - Horizontal method for the enumeration of microorganisms - Part 1: Colony count 
at 30 degrees $C$ by the pour plate technique. [https://www.iso.org/obp/ui/\#iso:std:iso:4833:-1:ed-1:v1:en].

[18] ISO 21527-1:2008(en). Microbiology of food and animal feeding stuffs Horizontal method for the enumeration of yeasts and moulds - Part 1: Colony count technique in products with water activity greater than 0.95. [https://www.iso.org/obp/ui/\#iso:std:iso:21527:-1:ed-1:v1:en].

[19] ISO 21527-2:2008(en). Microbiology of food and animal feeding stuffs Horizontal method for the enumeration of yeasts and moulds - Part 2: Colony count technique in products with water activity less than or equal to 0.95. [https://www.iso.org/obp/ui/\#iso:std:iso:21527:-2:ed-1:v1:en]. 


\section{Cited electronic references}

http://www.jlindquist.com/generalmicro/102aseptictechnique.html $\left(20^{\text {th }}\right.$ of March, 2017)

http://clinicalgate.com/principles-of-antimicrobial-use/ $\left(20^{\text {th }}\right.$ of March, 2017)

http://www.idfa.org (20 $0^{\text {th }}$ of March, 2017)

http://www.rodwell-autoclave.com/autoclave/monarch-autoclave/ $\left(20^{\text {th }}\right.$ of March, 2017)

http://www.nuve.com.tr/en/products/fn-032-055-120-dry-heat-sterilizersovens $\left(20^{\text {th }}\right.$ of March, 2017)

https://www.thermofisher.com/si/en/home.html (27 ${ }^{\text {th }}$ of March, 2017)

http://www.quickmedical.com/tuttnauer-manual-medical-autoclavesterilizer-valuklave-1730.html (20 $0^{\text {th }}$ of March, 2017)

https://www.thermofisher.com/si/en/home.html (20 of March, 2017)

https://www.kern-sohn.com/en/ (20 th of March, 2017)

http://labs-sl.domel.com/products-en/VIBROMIX-10-Vortex-186/ $\left(27^{\text {th }}\right.$ of March, 2017)

https://www.labsource.com/95-0367-01-bench-top-uv-sterilization-pcrworkstation.html $\left(27^{\text {th }}\right.$ of March, 2017)

http://www.merckmillipore.com (27 ${ }^{\text {th }}$ of March, 2017)

http://www.freeinfosociety.com/media.php?id=1250 (20 ${ }^{\text {th }}$ of March, 2017) 
https://quizlet.com/25963991/micro-q3-b2-strep-staph-bacillus-flashcards/ (20 ${ }^{\text {th }}$ of March, 2017)

http://www.celeromics.com (20 $0^{\text {th }}$ of March, 2017)

http://www.bd.com (20 of March, 2017) 
